\title{
To get the most out of high resolution X-ray tomography: a review of the post-reconstruction analysis
}

\author{
Yijin Liu, ${ }^{1,}$, Andrew M. Kiss ${ }^{1}$, Daniel H. Larsson ${ }^{1}$, Feifei Yang ${ }^{2}$, Piero Pianetta ${ }^{1}$ \\ ${ }^{1}$ Stanford Synchrotron Radiation Lightsource, SLAC National Accelerator Laboratory, \\ 2575 Sand Hill Road, Menlo Park, CA 94025, USA \\ ${ }^{2}$ Division of Biomaterials and Bioengineering, Department of Preventive and Restorative Dental Sciences, \\ UCSF, 707 Parnassus Avenue, San Francisco, CA 94143-0758, USA \\ *liuyijin@slac.stanford.edu
}

\begin{abstract}
X-ray microscopy has been well-recognized as one of the most important techniques for research in a wide range of scientific disciplines including materials science, geoscience, and bio-medical science. Advances in X-ray sources, optics, detectors, and imaging methodologies have made significant improvements to non-destructive reconstructions of the three dimensional (3D) structure of specimens over a wide range of length scales with different contrast mechanisms. A strength of 3D imaging is a "seeing is believing" way of reporting and analyzing data to better understand the structure/function characteristics of a sample. In addition to the excellent visualization capability, X-ray computed tomography has a lot more to offer. In this article, we review some of the experimental and analytical methods that enrich and extract scientifically relevant information from tomographic data. Several scientific cases are discussed along with how they enhance the tomographic dataset.
\end{abstract}

Keywords: X-ray; tomography; three-dimensional imaging; post-processing.

\section{Introduction}

X-rays have been used for imaging ever since they were discovered by Wilhelm Conrad Röntgen in the year 1895 [1]. One of the most attractive characteristics of X-rays is their penetration capability, which allows non-invasive probing of the specimen's internal structure. In the 1970s, Allan M. Cormack and Godfrey Newbold Hounsfield brought X-ray radiography into a new era with the ground breaking development of the computed tomography (CT) technique [2]. Using this technique, a series of projection images are acquired as the sample is rotated around an axis perpendicular to the incident $X$-rays. The 3D structure of the sample is then reconstructed numerically, which allows the internal features to be investigated while avoiding the uncertainty in a projection radiograph caused by overlapping features along the beam path.

Over the past few decades, the evolving tomography technique has had great impact in a wide range of scientific research areas and clinical applications. With the technological developments in X-ray components and improvements in imaging algorithms, the X-ray tomography technique is now capable of covering a wide range of length scales using different hardware configurations and utilizing different contrast mechanisms.

\subsection{X-ray microscopy configurations}

(C) 2016. This manuscript version is made available under the Elsevier user license http://www.elsevier.com/open-access/userlicense/1.0/ 
The most widely used tomography imaging system today is the medical-CT. Medical-CT [3] is designed to provide spatial resolution at the (sub) millimeter level and to cover a field of view of tens of centimeters. The configuration of a typical medical-CT system consists of an X-ray source, an area detector, and a sample placed in between. In order to collect a tomographic dataset, projection images must be recorded in different viewing angles. This can be done by either rotating the sample in the instrument, or designing the source-detector system to move around the fixed sample. For medical-CT applications, it is typically easier to move the source and detector to record images at different angles instead of rotating the sample (person). In the medical-CT configuration, spatial resolution is primarily determined by the detector pixel size, although other factors, such as the size of the X-ray source and the geometry of the imaging system, can affect the spatial resolution as well. Several approaches, a few are discussed below, can be used to increase the resolution of the system but they come at the cost of decreasing the field of view. It is important to consider what length scales are most important for the sample and how large of a volume needs to be imaged. With medical-CT scanners, a large field of view is needed and thus the spatial resolution is limited.

While medical-CT has achieved tremendous success in the medical and clinical applications, its limited spatial resolution becomes inadequate for research in many other scientific fields. In order to achieve higher spatial resolution beyond the size of the pixels in an X-ray area detector for the non-medical materials-specific applications, optical magnification was implemented by Flannery et al. in 1987 [4]. In this configuration, a scintillator screen is inserted downstream of the sample to convert the transmitted $\mathrm{X}$-rays into visible photons. The scintillator screen is optically coupled to an objective lens, which magnifies the image for recording using an optical camera, typically a charge-coupled device (CCD) detector. This configuration is usually referred to as micro-CT, as it offers spatial resolution down to the (sub) micron level. Since the optical lens and camera are employed in this configuration, the micro-CT's limitation in spatial resolution is ultimately limited by the wavelength of the visible photons emitted from the scintillator screen, which is typically at a few hundreds of nanometers [5]. Micro-CT has become a very powerful imaging tool with the advent of synchrotron radiation [6]-[14] and with improvements that have been made in laboratory-based sources [15].

For even higher spatial resolution down to the nano-scale regime (single to tens of nanometer spatial resolution), there are two popular approaches: objective zone plate based transmission X-ray microscopy (TXM) [16]-[26] and coherence based diffractive imaging [27], which includes plane wave coherent diffraction imaging (PCDI) [28], Fresnel coherent diffraction imaging (FCDI) [29], Bragg coherent diffraction imaging (BCDI) [30], and ptychography [31]-[35]. In the TXM case, a Fresnel zone plate is used to magnify the image by roughly 50 , which is currently limited by the technique used for fabricating Fresnel zone plates with large numerical aperture. Combining the magnification achieved in the X-ray regime with the optical magnifying system (similar to the micro-CT setup), the TXM can provide spatial resolutions down to ten(s) of nanometers [23], [25]. TXM has been demonstrated using both synchrotron radiation [23] and laboratory X-ray sources [36] and has been successfully applied in many scientific research fields.

In coherence based diffractive imaging, the sample is illuminated by the incoming coherent X-ray photons and diffraction patterns are recorded for quantitative phase retrieval using sophisticated numerical algorithms [37]. In principle, the spatial resolution of coherence based diffractive imaging 
should be able to reach the diffraction limit and, thus, is only limited by the wavelength of the incoming $\mathrm{X}$-rays. However there are other practical aspects of the experiment, such as the dynamic range of the detector [38], [39], the degree of coherence, motor errors, hardware stability, and radiation damage [40], [41], that typically reduce the effective spatial resolution. For a more comprehensive discussion of nanoscale X-ray imaging techniques, we refer to review articles by Sakdinawat and Attwood [42] and by Miao et al. [27].

\subsection{Contrast mechanisms}

X-ray microscopy can be configured to study a wide range of length scales and operate using different contrast modes. These contrast mechanisms include absorption contrast imaging, which can be directly quantified using the Beer-Lambert law [43]; phase contrast imaging [44], which offers significantly better contrast to specimens that are composed of low Z materials; dark field contrast imaging [45]-[47], which is related to the small angle scattering from fine features at sub-pixel scale; and chemical/elemental contrast imaging [16], [32], [48]-[53], when X-ray energy tunability is available. Chemical and elemental mapping can also be performed by using confocal X-ray fluorescence [54]-[57]. This technique, which can be performed in full-field [58] approaches but is more commonly used in scanning mode, can provide non-destructive elemental information about the sample. It is also worth mentioning that for raster-scanning based imaging methods (usually referred to as micro/nano probe [59]-[62], which are not the focus of this review), multiple contrast mechanisms can be accessed simultaneously providing very rich information of the specimen, although, the speed of data acquisition is usually slower than that of full-field imaging methods. The relatively low data collection rate is due to having to mechanically move the sample and raster scan over the entire region of interest. With the Xrays focused to a small spot size, a high resolution can be achieved. However, this will increase the number of points to scan over to collect the entire image. For this reason, these raster-based imaging techniques are most commonly used for $2 \mathrm{D}$ imaging and, thus, are not the focus of this review of highresolution X-ray tomography.

\subsection{Data preparation and pre-processing algorithms}

There are many algorithms developed for the reconstruction of tomographic data. The most widely used one is the filtered back projection (FBP) algorithm, which efficiently performs an inverse Radon transform [63] converting the projection data into a real-space 3D matrix of sample attenuation. More sophisticated iterative reconstruction algorithms, such as the algebraic reconstruction technique (ART) [64], maximum likelihood expectation maximization (MLEM) [65], ordered subset expectation maximization (OSEM) [66], compressed sensing (CS) based methods [67], [68], and equally sloped tomography (EST) [69] have been developed. These reconstruction algorithms strive to improve the signal-to-noise ratio (SNR) in the reconstructed 3D volume and to mitigate reconstruction artifacts, e.g. those caused by an incomplete or sparse angular sampling due to experimental constrains. These reconstruction algorithms have also been applied to other imaging techniques beyond X-ray microscopy such as electron microscopy [70].

In addition to the developments in reconstruction algorithms, research into methods for improved data pre- and post-processing is also very active. Examples include (1) several proposed methods to efficiently and automatically identify the center of rotation of the dataset [71]-[73], which is critical to the quality of the tomographic reconstruction; (2) image-registration and feature-identification 
algorithms, such as phase correlation [74], cross correlation [75], scale-invariant feature transform (SIFT) [76], [77], speeded up robust features (SURF) [78], that have been implemented in X-ray microscopy for stitching together of images in order to cover a larger sample area as well as aligning images for further investigation; (3) phase retrieval algorithms [79] that have been developed to quantitatively reconstruct the wave front prior to the tomography reconstruction; and (4) focus stacking algorithms, that have been implemented in X-ray microscopy to extend the depth of focus [80].

Once the volume has been reconstructed, it is critical for the post-processing steps that the data is segmented properly. Depending on the sample and system, this step ranges from being trivial to extremely complicated. There are many algorithms used for segmenting the data including two common segmenting methods: pixel value thresholding and watershed segmentation [81]. For some systems, it can be relatively easy to distinguish different material phases based on the pixel values. These systems can then be thresholded such that each material phase is identified by a range of pixel intensity values. This method was used for the data presented in Figure 4 by Nelson et al. [82], where the solid material can easily be distinguished from the pores. Unfortunately, this approach typically requires excellent image quality and if not done properly, there can be errors introduced which will affect the analysis. To help minimize this, algorithms such as the watershed algorithm [81] have been introduced. It makes use of the image intensity gradient information as well as the intensity values. By seeding different regions (based on pixel value), these regions will grow, filling the basins formed using the gradient information, until the entire volume is filled. This approach can help minimize segmentation errors and was used in the work shown in Figure 3 by Cronin et al. [83]. We would point out that when the data structure is more complicated (for example in phase contrast imaging experiments, where both the phase and amplitude can be retrieved) more sophisticated methods can be introduced for improving the quality of the segmentation [84]. Segmentation can yield quantitative measures of different sample properties, such as volume fraction, porosity, average particle diameter, etc. As different segmentation algorithms might arrive at different results, it is useful to compare such measurements with sample information that has been obtained in other ways. For example, the data presented in Figure 3 was compared to measurements done by focused ion beam milling and scanning electron microscopy (FIB-SEM) to provide confidence in the segmentation.

\subsection{Image quality assessment}

It is often useful to be able to quantify the image quality when, for example, optimizing experimental parameters. The signal-to-noise ratio (SNR) [85] is perhaps the most commonly used way to express image quality. The SNR is an objective measure of how much useful information an image contains and, therefore, a robust and general figure of merit. There are many different definitions of SNR and the appropriate formulation will vary depending on the properties of the object under study and the imaging arrangement used. In 1948, Albert Rose related SNR to the performance of a human observer by showing that an object is detectable by a human observer if the SNR is more than about 5 [86]. This detection limit is known as the Rose criterion [87]. A study by Patterson et al. [88] showed that as the number of radiographs increased, the background noise in the FBP reconstructions decreased. This improves the image slice quality by increasing the SNR and suggests that the segmentation and postprocessing would have a higher quality. Another common way to measure image quality is by estimating the achieved resolution from frequency analysis of the reconstructed 3D dataset. This can be done by 
Fourier shell correlation (FSC) [89], [90], which measures the cross correlation of 3D images as a function of spatial frequency. These methods allow the quantitative assessment of the image quality, which is very important to ensure the quality of further evaluation and analysis.

\subsection{Beyond the 3D reconstruction}

As discussed above, recent years have seen enormous development in the methodology for X-ray microscopy, both in regards to hardware configuration and implementation, as well as data processing which includes tomographic reconstruction. While it is extremely important to handle the X-ray microscopic data acquisition and reconstruction carefully to ensure the highest quality and fidelity of the reconstructed 3D matrix, it is also critical to analyze and interpret the reconstructed 3D volume properly. In this article, we focus on the discussion of post-reconstruction and post-segmentation analysis methods, which are defined here as the procedures that take the reconstructed 3D volume as input and generate scientifically relevant information. Several of these post-reconstruction methods, as well as their recent applications, will be discussed in detail.

\section{Direct observation}

As an important branch in the family of imaging technologies, X-ray microscopy offers excellent capability of real-space visualization of the sample structure in 3D. As a result, "direct observation" of the 3D dataset is a simple, yet powerful way to interpret the data. Two scientific case studies highlighting the strength of direct visualization are presented below.

One example in the field of geoscience is an investigation of the morphology of molten iron at underground conditions, as mimicked by using a diamond anvil cell and laser heating system [91]. The Earth's well-known layered structure, with a metallic core and overlying silicate mantle, suggests that some mechanisms are causing the separation of iron alloys from silicates. Various mechanisms have been proposed, which could be directly confirmed or rejected, by the direct observation of the morphology of the iron melt. Shi et al. [91] studied the mixture of the iron alloy and the enstatite that was exposed to upper and lower mantle temperature and pressure, and then quenched to room temperature rapidly with the morphology of the iron melt preserved. Hard X-ray nano-tomography allowed direct visualization of the iron distribution as presented in Figure 1. In the selected regions of interest, the Fe melt changes from isolated pockets at 25 and $39 \mathrm{GPa}$ to an interconnected network at 52 and $64 \mathrm{GPa}$. This indicates that percolation could be a viable mechanism for core formation at the Earth's lower mantle conditions, which is an important piece of information that could help understanding the core formation. 

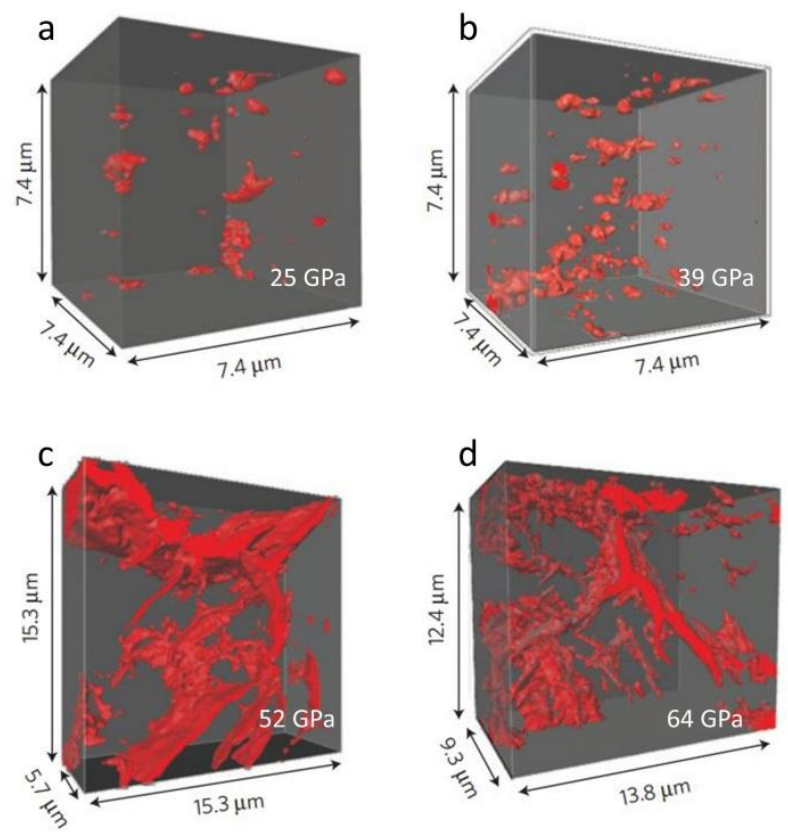

Figure 1. 3D distribution of iron alloy melt in silicate perovskite visualized using zone plate based X-ray nano-tomography. The samples were synthesized at $25 \mathrm{GPa}$ (a), $39 \mathrm{GPa}$ (b), $52 \mathrm{GPa}$ (c) and $64 \mathrm{GPa}$ (d). The scales of each selected volume of interest are labelled. (Figure reproduced from [91] with permission from Nature Publishing Group.)

Another example of "direct observation" in biological applications using X-ray tomography is the study of the effect that nuclear aggregation of genes has on their expression [92]. It is believed that the gene positioning and regulation of nuclear architecture influences the gene expression. Powerful optical microscopy techniques, such as optical confocal microscopy [93] and super-resolved fluorescence microscopy [94], [95], have been widely used in the field of bioscience. However, it remains very challenging to obtain 3D high resolution (down to nanometer scale) structural information of whole cell samples, especially when working with fully hydrated, unfixed, and unstained cells. In X-ray nanotomography experiments, biological samples are usually quickly frozen in liquid nitrogen, allowing the preservation of the cell structure, and mounted in a cryogenic gas stream, which keeps the specimen under cryogenic conditions during the tomographic data acquisition [96], [97]. In the study by Clowney et al. [92], chromatin in control and ectopically expressed olfactory sensory neurons were imaged using water-window X-ray nano-tomography. Using this method, the energy of the incident X-rays is between the K-shell absorption edges of carbon at $284 \mathrm{eV}$ and that of oxygen at $543 \mathrm{eV}$. Imaging between these two absorption edges allows for a relatively high absorption in any carbon containing regions (the chromatin), while oxygen rich areas (water) will appear relatively transparent. This is beneficial for many biological species because carbon rich structures can be seen with a high contrast over the transparent water. As shown in Figure 2, significant differences in chromatin location between the two neurons can be observed. Relocation of the most condensed chromatin toward the nuclear membrane is clearly observed in the ectopically expressed neuron, providing direct visualization of the structural and biophysical changes that occur in the neuron upon the specifically introduced ectopic expression. 


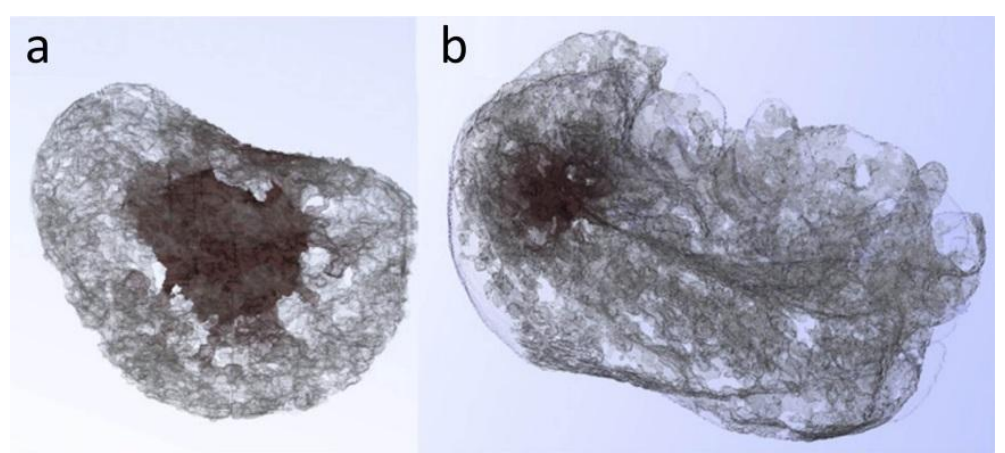

Figure 2. Soft X-ray tomography of olfactory sensory neurons demonstrates chromatin decompaction and nuclear reorganization upon specifically induced ectopic expression. Panel $a$ is the rendering of a control neuron and panel $b$ is the rendering of ectopically expressed neuron. (Figure reproduced from [92] with permission from Elsevier.)

For direct observations that can lead to the answers to scientific questions, it is critical to make sure that image data is acquired at the scientifically relevant length scales. It is very difficult, if not impossible, to achieve both high spatial resolution and large field of view at the same time. As a result, it is crucial to choose the right imaging method based on the size of the features of interest. In many cases, multiple $X$-ray imaging techniques need to be combined in order to provide structural information across several length scales. X-ray tomography at a larger length scale can often be used to survey the sample and to identify regions of interest for more detailed investigation. Technical challenges in both the experimental and analytical aspects of such experiments, such as correlative imaging setups [71] and local tomography algorithms [98], respectively, need to be carefully addressed.

\section{Morphological quantification}

As discussed in the section above, direct visualization of the 3D structure can provide straightforward and qualitative evidence for many scientific case studies. However, it is often desirable to interpret the reconstructed 3D structural data in a quantitative manner. For example, it can be difficult to extract solid and statistically meaningful information by direct visualization in studies of hierarchically structured heterogeneous systems. In these types of scientific studies, morphological quantification becomes very important. Here we define "morphological quantification" as a type of numerical method that calculates certain morphological parameters from the reconstructed 3D tomography data, for quantifying certain aspects of the sample structure. These morphological parameters include, but are not limited to, phase volume fraction (including porosity) [99]-[102], surface area [100], [102]-[105], particle size distribution [106], phase connectivity [100], [104], [105], triple phase boundaries (TPB) [101], [107], tortuosity [100], [105], [108], pore throat size distributions [109], phase complexity [110], [111], channel diameter distribution [112], minimum representative volume [109], [113], fractal dimensions [102]. A selected case study, which highlights the applications of morphological quantification in the investigation of solid oxide fuel cells (SOFCs) using X-ray tomography, is discussed below.

As an example of "morphological quantification", we discuss here the work by Cronin et al. [83], in which detailed structural investigation is performed on the 3D micro-morphology of an entire active region of an anode-supported SOFC that is reconstructed using hard X-ray nano-tomography. SOFCs are electrochemical conversion devices that directly utilize the electron transfer while oxidizing a fuel. They 
often contain complex composite structures for both the anode and cathode. The electrode's microstructure is believed to be an important factor that greatly affects the electrochemical performance, and thus the performance of the entire cell. Due to the complexity of the 3D micromorphology of the electrode, it is essential to image the SOFC sample with high spatial resolution and over a large volume of interest (see Figure 3a), leading to difficulties in drawing unambiguous conclusions by direct visualization using the human eye. The ultimate goal to link micro-morphology to macroscopic performance also requires quantitative analysis to provide insight with the help of statistics. In this work, several morphological parameters (as shown in Table 1) are calculated with the input from nano-tomography. Comparing these quantification results to previous reports using the FIB-SEM technique, while showing good overall agreement, the results presented in this work show higher pore connectivity of the studied anodes leading to a higher percentage of active triple-phase boundaries (TPBs), which is critical information to assess cell performance. Visualization of the TPBs over a small sub-volume is shown in Figure $2 b$.

(a)

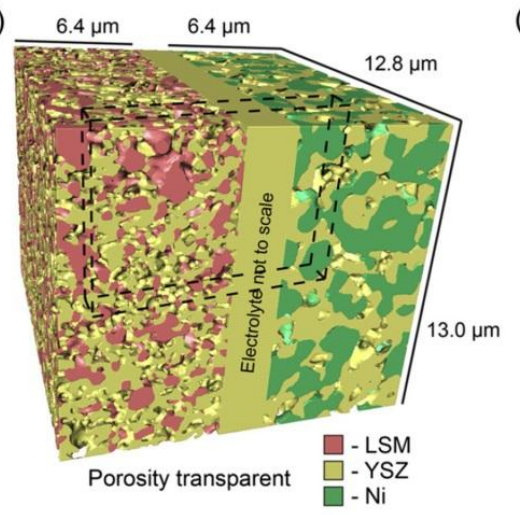

(b)

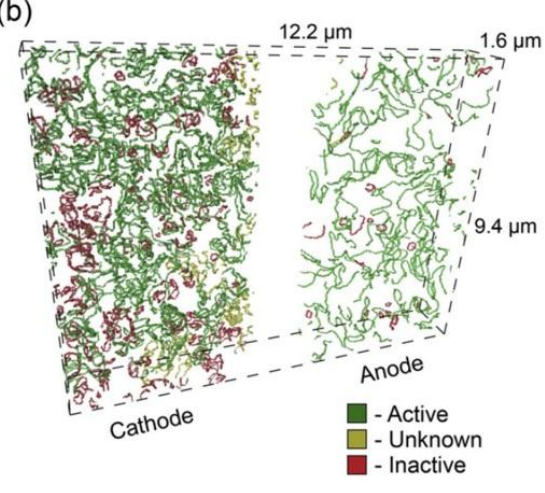

Figure 3. Hard X-ray nano-tomography of a SOFC structure, with the cathode on the left and anode on the right. Panel (a) shows the solid phases and (b) shows the triple phase boundary (TPB) lines. (Figure reproduced from [83] with permission from Elsevier.)

Table 1. Quantification of 3D morphological parameters for the SOFC electrodes. (Table reproduced from [83] with permission from Elsevier.)

\begin{tabular}{|c|c|c|c|}
\hline \multicolumn{2}{|l|}{ Anode } & \multicolumn{2}{|l|}{ Cathode } \\
\hline \multicolumn{4}{|c|}{ Volume analyzed $\left(\mu \mathrm{m}^{3}\right)$} \\
\hline Anode & 3641 & Cathode & 4118 \\
\hline \multicolumn{4}{|c|}{ Phase volume fractions (\%) } \\
\hline $\mathrm{Ni}$ & 36.9 & LSM & 23.1 \\
\hline YSZ & 40.1 & YSZ & 26.3 \\
\hline Pore & 23.0 & Pore & 50.6 \\
\hline \multicolumn{4}{|c|}{ Specific surface area $\left(\mu m^{2} / \mu m^{3}\right)$} \\
\hline $\mathrm{Ni}$ & 4.11 & LSM & 9.51 \\
\hline YSZ & 6.01 & YSZ & 12.63 \\
\hline Pore & 7.56 & Pore & 7.86 \\
\hline \multicolumn{4}{|c|}{ Interfacial areas $\left(\mu m^{2} / \mu m^{3}\right)$} \\
\hline Ni-YSZ & 1.09 & LSM-YSZ & 0.77 \\
\hline YSZ-pore & 1.31 & LSZ-pore & 2.55 \\
\hline
\end{tabular}




\begin{tabular}{lcll} 
Ni-pore & 0.42 & LSM-pore & 1.43 \\
Volume fraction connected $(\%)$ & & \\
$\mathrm{Ni}$ & 99.3 & LSM & 76.2 \\
YSZ & 100.0 & YSZ & 98.2 \\
Pore & 98.8 & Pore & 100.0 \\
$T P B$ density $\left(\mu \mathrm{m} / \mu \mathrm{m}^{3}\right)$ & & & \\
Total & 3.06 & Total & 10.24 \\
Active & 2.89 & Active & 6.73 \\
Inactive & 0.17 & Inactive & 3.51 \\
\hline
\end{tabular}

The morphological quantification is very powerful for statistical analysis of hierarchically complex structures. One thing that needs to be pointed out is that it is critical to make sure the amount of sampling is large enough to be statistically representative. Several studies in the literature have been using the evaluation of porosity as a function of total volume to assess the "minimum representative volume" [109], [113]. However, further investigation into assessing the degree of representativeness is still desirable, as the porosity is certainly not solely responsible for all the macroscopic properties of the material under investigation. There have been studies which attempt to quantify the minimum representative volume element size by studying the volume dependency of morphological parameters such as volume fraction, phase size distribution and network contiguity [114], [115]. This type of evaluations is critical for ensuring the scalability of the findings concluded from the microscopic data.

\section{Network extraction and analysis}

The 3D morphology of hierarchically structured porous media and functional materials is usually rather complex. While one could perform morphological quantification on the tomographic data as discussed in the previous section, it is often useful to reconstruct a topologically representative network from the tomography data for further analysis. Such network extraction and analysis require extensive image preprocessing to discretize the complicatedly structured material phase into simple geometrical objects, typically represented by nodes and bonds. Each extracted geometrical object is usually assigned a set of effective geometrical parameters, such as length, radius, curvature, etc. The extracted geometrical network represents the complex 3D morphology and simplifies the following modeling work to predict several phenomena, e.g. mass transport [116], relative permeability [117], [118], pore network accessibility [119], capillary pressure [120], and electronic/ionic conduction [82], [121], [122].

Careful analysis of the segmented structure identifies junctions, or nodes, which are joined by different bonds. These bonds can be characterized as geometric objects which can be analyzed easier and more quickly than the original complex structure. For example, the work of Nelson et al. [82] was able to retrieve analytical solutions for conduction and surface reactions of several types of extended surfaces, such as cones and spheres. Each bond is categorized as a type of extended surface, and analytical solutions are calculated. This representation of a structure as a node and bond network can decrease necessary computing requirements compared to discretizing modeling tools such as finite element analysis (FEA). With these lower computing requirements, larger volumes can be studied which can provide a more representative volume element. 


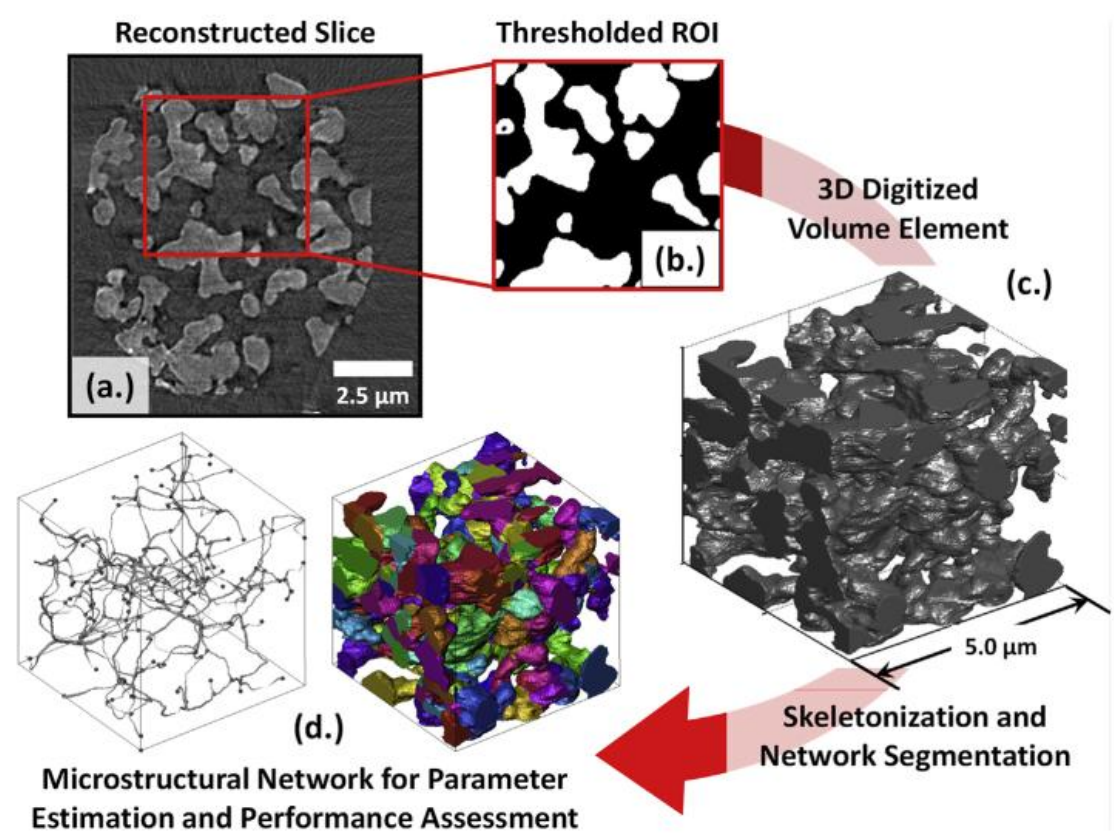

Figure 4: A workflow for processing reconstructed data to identify individual objects and create a node and bond network. (Figure reproduced from [82] with permission from Elsevier.)

While these node and bond systems can be beneficial for simplifying a system and results can agree with experimental and numerical results, there is a wealth of localized data which is lost during the network creation. By restricting bonds to have predefined geometric shapes, the structure will not be exactly captured, leading to some error in the final result. Using FEA, the discretization step will more accurately represent the structure at the cost of computational resources. Having analytical solutions to different bonds is computationally fast, but requires that the equations between the nodes properly represent the physics for the system by not neglecting any significant mechanisms and still solving for the governing equations. With a commercial FEA package, it is relatively easy to add or remove these physics as necessary and still solve the equations numerically. The biggest strengths of this node and bond system method are its ability to transform a complex system into an easily solvable network to obtain results quickly and with less computing resources than when using other discretizing methods.

\section{Tomography with X-ray energy tunability}

The above-discussed post-reconstruction analysis methods all focus on the 3D morphology of the sample as retrieved using X-ray tomography. It is worth emphasizing that X-rays can offer additional elemental and chemical information when energy tunability is available.

\subsection{Tomography with elemental specificity}

One of the most straightforward ways to take advantage of this feature is to collect tomographic data above and below an absorption edge of the element of interest. By comparing the images above and below the edge, an elemental map can be produced based on the absorption changes. This technique can be extended to several absorption edges in order to locate more than one element. The changes in absorption coefficient and, thus, in image contrast at different X-ray energies directly associate with the 
distribution of the element of interest, which could be an intrinsic part of the sample, or an added tracer element.

This strategy has been applied in many studies such as synchrotron based bio-medical imaging, microtomography, and X-ray nano-tomography. In the bio-medical imaging application, the researchers were able to image at a relatively large length scale and use iodine's K-absorption edge in order to enhance the image contrast in transvenous coronary angiography [123]. For a more detailed and systematic review of the application of dual-energy tomography for medical and clinical applications, please refer to the article by Karçaaaltınçaba and Aktaş [124]. This dual energy imaging approach has also been used in the geosciences with a micro-tomography system where xenon was used as a tracer to study the accessibility of the complex pore network in sandstones, carbonates, and shales and coal [50]. This technique also extends to X-ray nano-tomography for studying integrated circuits [52], battery electrode materials [110], [125], [126], industrial catalysis particles [119], [127]-[129], man-made magnetic materials [130], and solid oxide fuel cell electrodes [101], [131]. Recent developments have also demonstrated this duel energy approach with ptychography [132].

As an example of a scientific case study using tomography with elemental specificity, we discuss the work by Yang et al. [110], where a type of promising high energy density lithium-manganese rich Li-ion cathode material was systematically studied using synchrotron based nano-tomography. The research in rechargeable Li-ion devices has been very active in the past decades because of the important role they play in nearly all aspects of modern life. Understanding the evolution of chemical composition and morphology of battery materials during electrochemical cycling is fundamental to extending battery cycle life and ensuring safety. In this work [110], a systematic investigation of the morphology and elemental distribution within secondary-particles, which are agglomerate of primary particles with size at about 100 nanometers, shows that this cathode material exhibits interesting 3D morphological changes and transition metal depletion at the particle surface, after just one cycle, and to a greater extent after 200 cycles. Direct observation of the 3D rendering and morphological quantification (Figure 5) clearly show that transition metal migration occurs in this particular type of cathode material as the battery is electrochemically cycled, which could be one of the reasons for cathode degradation.
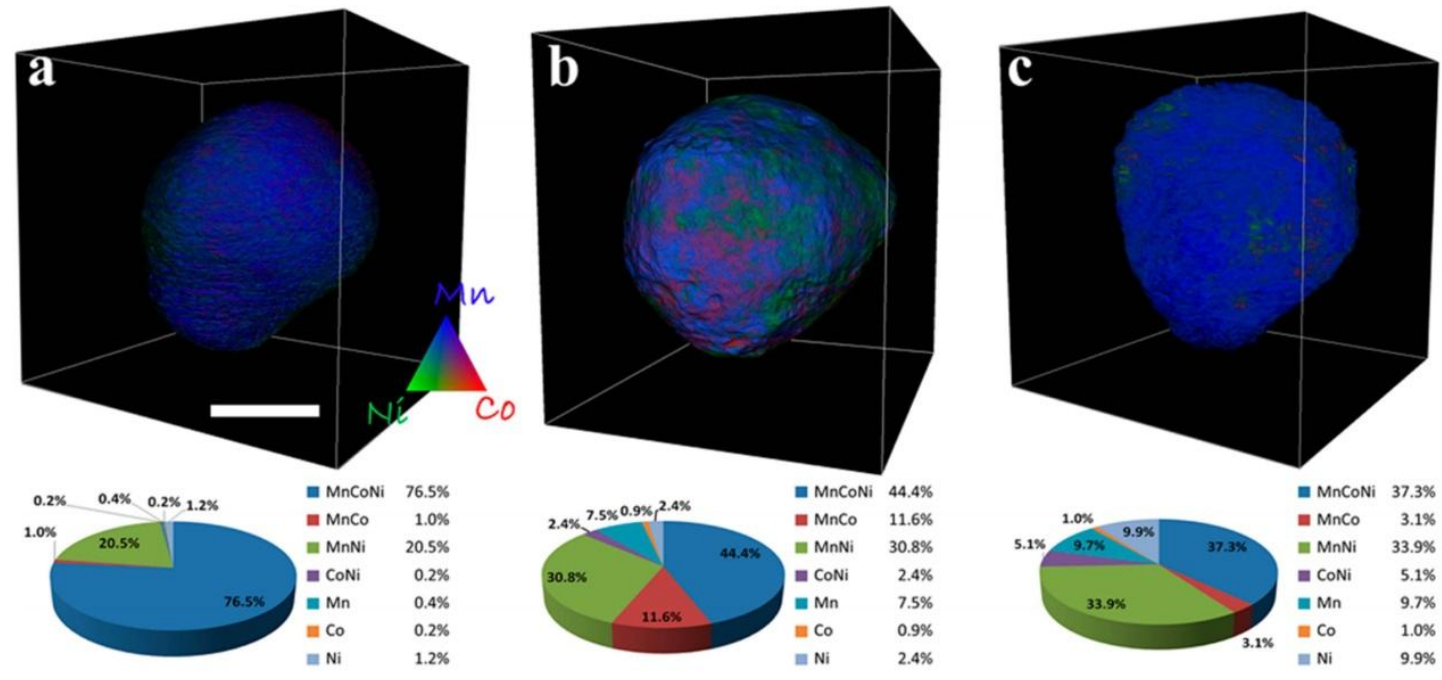

Figure 5: Elemental association maps of NMC cathode secondary particles selected from the pristine (panel a), 1× cycled (panel b), and 200× cycled (panel c) electrodes. The top row shows the 3D rendering 
of the elemental distribution; the bottom row shows the relative concentration of different elemental associations within the corresponding particles. The scale bar is 5 micrometers. (Figure reproduced from [110] with permission from American Chemical Society.)

Transmission X-ray tomography with elemental sensitivity has been successfully applied in many research fields. However, there are still a few limitations including (1) the limited sensitivity, which requires high-enough local concentration for detection; and (2) limited applicability to elements of interest due to the constraints set by the attenuation length of the sample at the desired X-ray energies. It is often useful to carry out theoretical calculations to predict the amount of transmission and image contrast before the experiment with some prior knowledge of the sample, e.g. the average composition of the material.

\subsection{Tomography with chemical sensitivity}

In many scientific case studies, the distributions of different chemical components (e.g. chemical species with the same element of interest, but in different oxidation states) are of interest. X-ray spectroscopy can be combined with the full-field imaging technique [51], [53], [133], [134] to retrieve the spatial distributions of the chemical species. In this type of experiment, full-field X-ray radiographs are collected as the energy of the incoming X-rays is tuned to several points across the absorption edge of interest. The fact that 2D pixel array area detectors are used in the imaging data acquisition makes data acquisition significantly faster compared to the raster-scanning-based fluorescence mapping methods. After the image matrices have been spatially registered with respect to each other, this multipledimensional dataset can be treated as spatially resolved spectroscopic data. The standard numerical methods for preparing and quantifying the X-ray spectroscopic data can then be applied. For example, normalization of the X-ray spectrum can be performed in a few different ways [135]-[138] to separate the concentration of the element of interest from the data as a piece of information independent of the chemical speciation and to prepare the spectrum for further quantitative analysis such as linear combination fitting of known standards [134] and principal component analysis [139], [140]. The work by Meirer et al. [134] is discussed below as an example of the application of X-ray nano-tomography with chemical sensitivity.

In the operation of Li-ion batteries, the extraction (or insertion) of Li ions from (to) the electrode leads to complex local electrochemical reactions and mechanical stress, which results in morphological and chemical changes at fine length scales. For better design of battery materials, it is very desirable to visualize the battery electrode in 3D at relevant length scales with chemical sensitivity. In this study, Meirer et al. [134] combined Fresnel zone plate based nano-tomography with the energy tunability enabled by a third generation synchrotron to perform the 3D-XANES (3D X-ray Absorption Near Edge Structure) measurement. As shown in Figure 6, partially reduced Ni-rich battery electrode particles were studied using this method allowing the visualization of different chemical species that heterogeneously co-exist at the sub-particle length scale. A 2D slice (Figure 6b) through the center of the particle also shows the complex reaction front as indicated by the blue voxels which show mixed valence states at this length scale, possibly caused by subpixel heterogeneity. The work presented in this paper studied battery electrodes, however its versatility is believed to be able to impact a number of diverse research fields. 

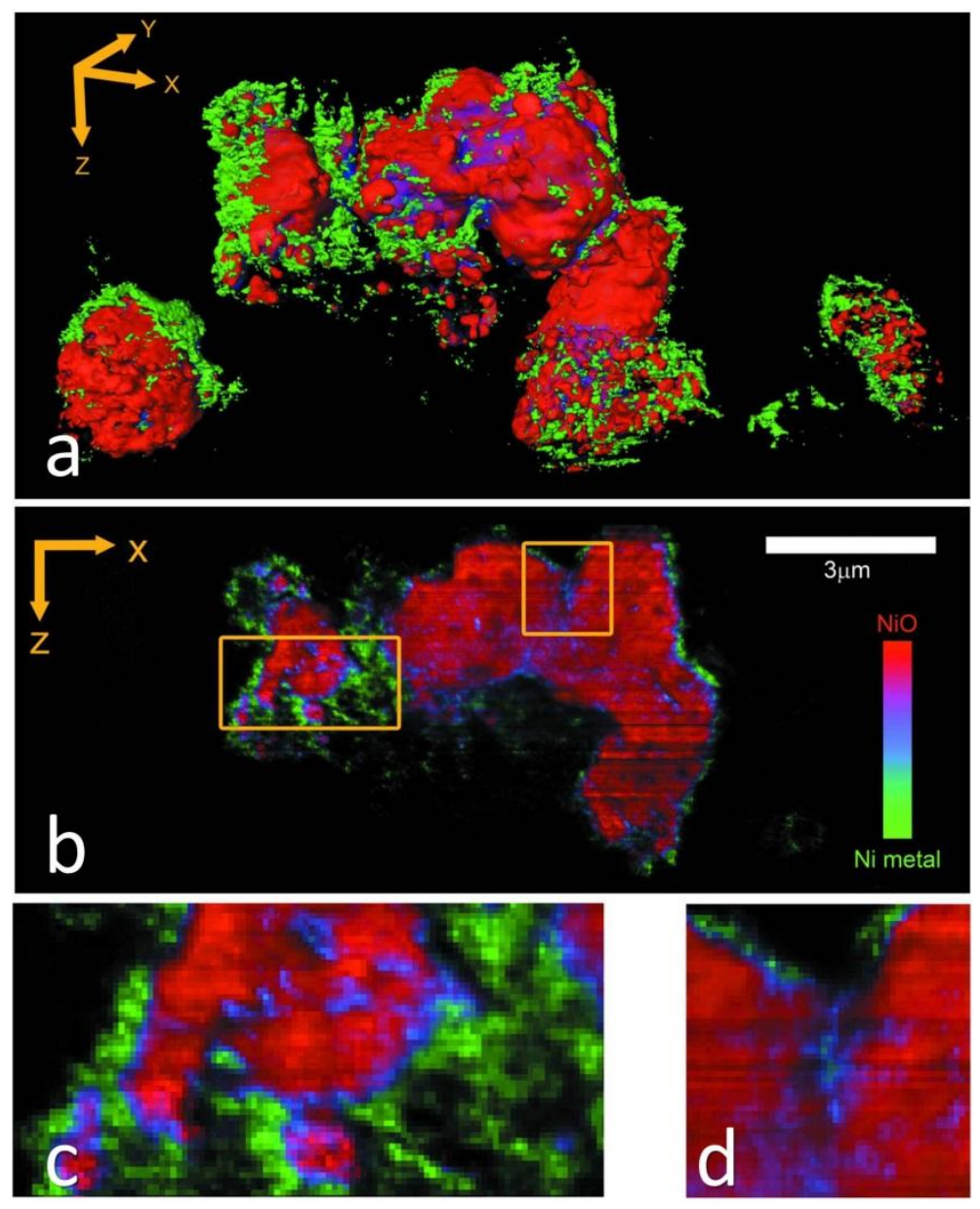

Figure 6. 3D visualization of partially reduced battery electrode particles with chemical sensitivity. Panel $a$ is the perspective rendering of three-dimensional data set of the electrode particle. Panel $b$ is $a$ single-voxel-thick slice through the center of the 3D matrix with magnified views of the highlighted areas shown in panels $\mathrm{c}$ and $\mathrm{d}$. (Figure reproduced from [134] with permission from IUCr Journals.)

\subsection{Tomography with Data-Constrained Modeling}

It is worth mentioning that imaging across absorption edges is not always applicable in many scientific case studies. For example, in many geological studies, the sample is relatively large and requires high energy X-rays at tens of keV for sufficient penetration. However, the geological formations mostly consist of quartz and carbonate minerals, such as calcite and dolomite, with no absorption edge in this energy range. In this case, having some prior knowledge of the model compounds, the energy dependency of the absorption coefficient (reconstructed by performing tomography at two or more X-ray energies) can still provide useful information to distinguish different mineral phases and to understand the distribution of different physical properties. More examples of this type of postreconstruction analysis, also known as data-constrained modeling (DCM), can be found in the literature [141]-[144].

\section{Correlative imaging}


As discussed above, the full-field transmission X-ray tomography data is very informative and can be handled in many different ways depending on the needs of the particular scientific case. However, information on other sample properties, which are beyond the scope of what transmission X-ray tomography can offer (e.g. crystal grain orientation, fluorescence fingerprint), could be very desirable in some studies. As a result, many varieties of correlative imaging are being actively developed. Here we discuss two types of correlative imaging methods: diffraction contrast tomography and correlative fluorescence and transmission tomography.

\subsection{Diffraction Contrast Tomography}

One of the correlative imaging methods is diffraction contrast tomography (DCT) [145]-[148]. The DCT experimental setup is very similar to a conventional X-ray tomography setup, but with a larger area detector. This larger detector is able to capture the occasionally occurring diffraction spot when a certain grain within the polycrystalline sample fulfills the Bragg condition as the sample is rotated. DCT is listed here as one type of correlative imaging because one usually acquires traditional transmission data and the diffraction patterns simultaneously. Transmission in-line phase contrast tomography data can be used to perform conventional tomographic reconstruction and thus, to define the shape of the sample; while images recorded by the large diffraction detector in selected viewing angles, where Bragg diffraction from certain grains occur, can be used to reconstruct the individual grains. Since the sampledetector geometry is well defined, the orientation of individual grains can be retrieved in addition to their 3D shape. The DCT method has also been extended to laboratory X-ray sources [149] and neutron sources [150]. A study by Ludwig et al. [151] is discussed below as an example to show the capability of this method.

The solid bulk materials that we encounter in our daily life are usually polycrystalline. Structural properties, including the shape, size, and relative orientation, of the crystal grains within the solid material directly affect its macroscopic behavior and, thus, structural information is important for the design of almost everything that we use in our daily life. Ludwig et al. [151] presented a study of the mechanical failure of a piece of polycrystalline alumina by intergranular brittle fracture. In this study, correlative X-ray transmission tomography and diffraction contrast tomography were performed prior to in situ mechanical compression loading. As shown in Figure 7a, some void defects already exist in the material before loading, mainly located at grain boundaries and boundary triple junctions. The sample was compressed and several tomograms acquired under increasing load. The cracking that developed during the final loading increment can be seen in Figure 7b. An overlay of the DCT result and the transmission tomography result (Figure 7c) reveals the intergranular character of the crack, which is caused by the combined effect of compression and residual strains arising. In this case, DCT provides valuable information that allows the analysis of grain boundary characteristics, which plays an important role in the failure of the material. 

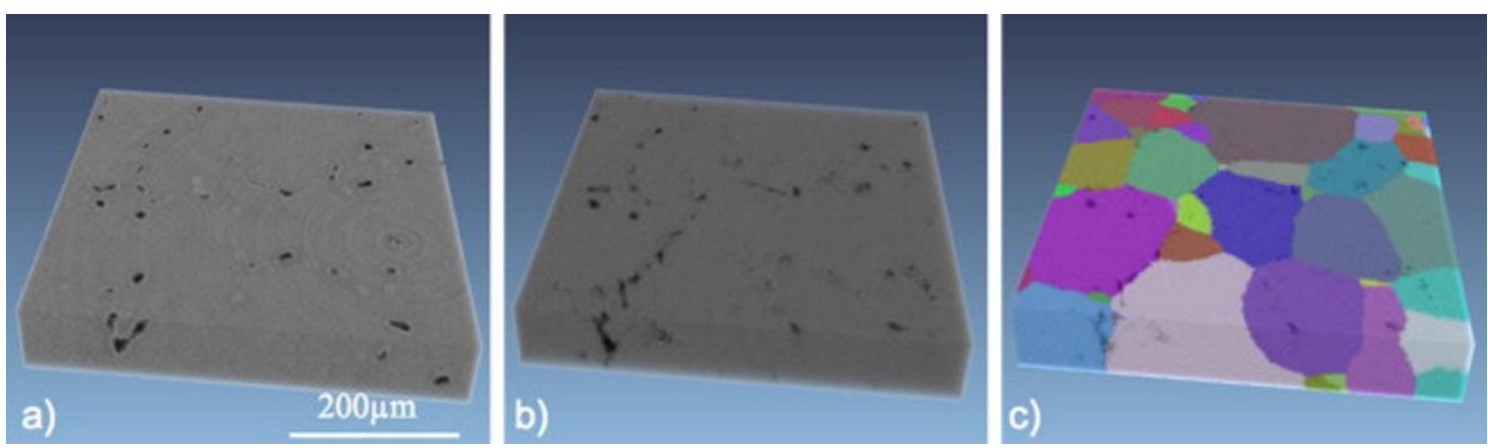

Figure 7. 3D visualization of a piece of polycrystalline alumina material. Panel a is the 3D rendering of the starting material. Panel $b$ is the same sample after mechanical loading, which leads to the formation of cracks as observed in the rendering. Panel $\mathrm{c}$ is the overlay of the diffraction contrast tomography result and the transmission $\mathrm{X}$-ray tomography result. (Figure reproduced from [151] with permission from Elsevier.)

\subsection{Correlative Fluorescence and Transmission Tomography}

Another exciting correlative imaging technique is the correlative fluorescence and transmission imaging. Fluorescence imaging methods, in both the X-ray and visible light regime, are known to be superior in terms of sensitivity to chemical species at low concentration. Correlative fluorescence and transmission tomography shows great advantages because the complementary information provided by the two modalities contributes to a more complete understanding of the specimen. There are several demonstrations including the combinations of full-field X-ray nano-tomography and a scanning X-ray nanoprobe [152], ptychography and X-ray fluorescence microscopy [31], and full-field X-ray nanotomography and confocal (visible) fluorescence tomography [153]. The work by Smith et al. [153] is discussed below as an example of correlative fluorescence and transmission tomography.

It has been demonstrated that X-ray nano-tomography that operates in the so-called water window (284-543 eV) can noninvasively reconstruct 3D structure of whole cells with sufficient spatial resolution and absorption contrast that allows for detailed investigation of the subcellular structures [24], [154]. However, the scientific interpretation of the structural data is usually not straightforward. It is well known that specific fluorescence labeling can aim for a particular target and thus, can be used for understanding a certain functional unit in bio-systems. Smith et al. [153] combined full-field X-ray nanotomography and confocal (visible) fluorescence tomography to visualize the topological arrangement of the inactive $X$-chromosome in rapidly-frozen mouse thymic lymphoma cells. The 3D volume of the inactive X-chromosome can be clearly visualized and quantified once it is identified by the confocal (visible) fluorescence tomography and segmented from the high resolution structural data retrieved by full-field X-ray nano-tomography. With this correlative approach, structural imaging and functional imaging can be nicely combined allowing more sophisticated analysis. 

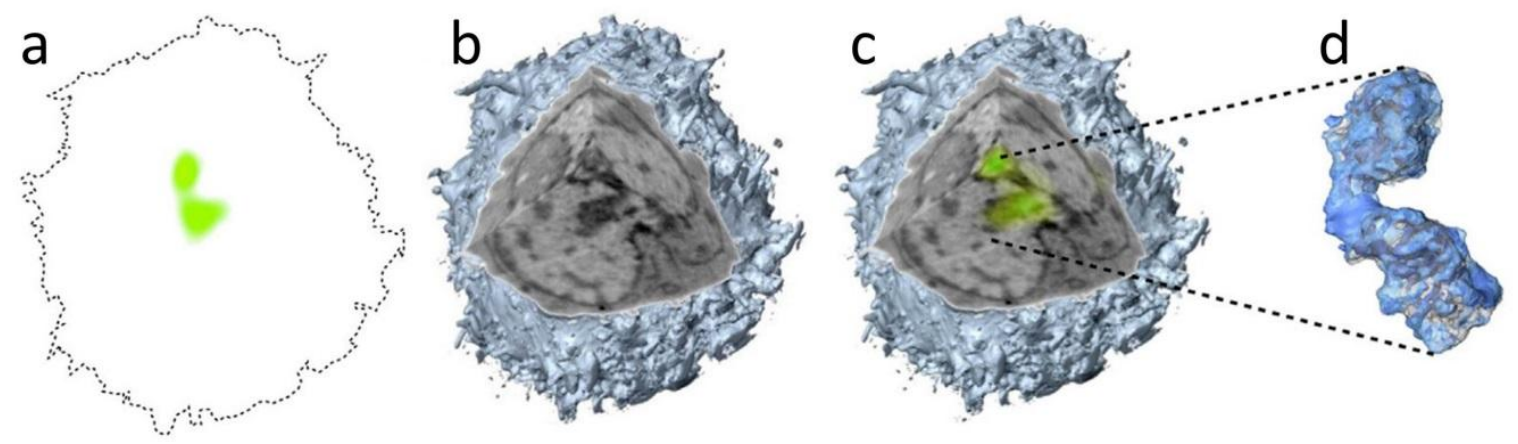

Figure 8: 3D correlative full-field X-ray nano-tomography and confocal (visible) fluorescence tomography imaging of a mouse thymic lymphoma cell. Panel a is the reconstructed fluorescence signal within the cell. Panel $b$ is the full-field $X$-ray nano-tomography result. Panel c shows the overlay of panels $a$ and $b$, emphasizing the correlative nature of these two datasets. Panel $d$ is the magnified view of the inactive $X$ chromosome, which is identified by the (visible) florescence labeling and is segmented from the full-field X-ray nano-tomography data. The diameter of the cell is estimated to be $500-600 \mathrm{~nm}$ (Figure reproduced from [153] with permission from Elsevier.)

\section{Discussions and conclusion}

X-ray tomography has been playing an important role in many research fields, including geoscience [155], materials science [156], soil science [157], [158], and bioscience [159]. The full-field transmission $\mathrm{X}$-ray tomography data can provide very rich information and can be handled in many different ways depending on the needs of the particular scientific case. In this article, we have reviewed several experimental and analytical methods that enrich and extract scientifically relevant information from fullfield X-ray tomographic data. We also would like to bring up a few important points about the limitations and future developments.

\subsection{In situ capabilities}

Due to the penetration capability of X-rays, X-ray tomographic investigations can often be conducted under controlled sample environments, which add an additional dimension to the experimental data that is relevant to the scientific case. Some examples include studies of (1) geological formations at mimicked underground conditions [160], [161]; (2) battery electrodes during electrochemical cycling [10], [111], [162], [163]; (3) thermal and strain [164], [165]; and (4) materials under extreme pressure [166]-[170]. The post-reconstruction analytical methods discussed above can certainly be combined with in situ capabilities to provide valuable insights into the complex processes that are relevant to the corresponding scientific case.

\subsection{Radiation dose associated with the measurement}

One of the major concerns in the application of X-ray tomography is the radiation dose associated with the measurement. This is not only critical for medical and clinical applications[171], [172], but also for other research fields, such as energy materials science [173]-[175]. For many applications the radiation dose also sets the practical limit for the spatial resolution [40], [41]. Although the dose fractionation theorem [176] suggests that, compared to 2D projection imaging, a well-designed tomography experiment should not add any burden in terms of radiation dose when targeting the same spatial resolution, an advanced tomography data acquisition and processing strategy is critical to managing the 
dose associated with the experiment and ensuring that the observed structure or chemistry is free of artifacts caused by radiation damage. Another possible solution to reduce the total dose is to improve the contrast by applying contrast agents [177] and thus, reduce the total exposure time on the sample. However, this approach must be used with extra caution as artifacts could be introduced.

\subsection{X-ray synchrotron facilities}

As discussed above, the advance in the capability of X-ray imaging is largely facilitated by the development of novel X-ray sources, especially the large X-ray facilities such as synchrotrons. Currently there are nearly 50 synchrotron radiation facilities all over the world. A lot of useful information can be found at www.lightsources.org, including links to individual facilities' web pages, where descriptions of available imaging modalities and techniques are listed. Many of these facilities are undergoing or have proposed upgrade plans towards a new generation of synchrotron facilities with higher flux, better coherence and lower emittance. With the improved performance we expect that novel imaging techniques as well as their applications in different research fields will continue to advance.

To summarize, X-ray tomographic data offers a great amount of scientifically relevant information at a range of length scales using different contrast mechanisms. This information can be analyzed and enhanced using properly designed experimental and analytical methods. With the ongoing developments in X-ray sources, optics [178], [179], detectors, and imaging methodologies, we have no doubt that the applications of $X$-ray tomography will continue to grow significantly.

\section{Acknowledgement}

The authors gratefully acknowledge Dr. A. Sakdinawat, Dr. J. Nelson Weker and Dr. D. Van Campen from SLAC National Accelerator Laboratory for valuable discussions. A. M. K. acknowledges financial support from a SLAC LDRD program. D. H. L. acknowledges financial support from the Wallenberg foundation. F. Y. acknowledges financial support from NIH/NIDCR-R01DE022032 (SPH). Stanford Synchrotron Radiation Lightsource, SLAC National Accelerator Laboratory, is supported by the U.S. Department of Energy, Office of Science, Office of Basic Energy Sciences under Contract No. DE-AC02-76SF00515.

\section{Reference}

[1] R. I. Frankel, “Centennial of Röntgen's discovery of x-rays.,” West. J. Med., vol. 164, no. 6, pp. 497-501, Jun. 1996.

[2] W. Bautz and W. Kalender, "Godfrey N. Hounsfield and his influence on radiology.," Radiologe, vol. 45, no. 4, pp. 350-5, Apr. 2005.

[3] L. W. Goldman, "Principles of CT: multislice CT.," J. Nucl. Med. Technol., vol. 36, no. 2, pp. 57-68; quiz 75-6, Jun. 2008.

[4] B. P. Flannery, H. W. Deckman, W. G. Roberge, and K. L. D’Amico, "Three-Dimensional X-ray Microtomography.," Science, vol. 237, no. 4821, pp. 1439-44, Sep. 1987.

[5] T. Martin, P.-A. Douissard, M. Couchaud, A. Cecilia, T. Baumbach, K. Dupre, and A. Rack, "LSOBased Single Crystal Film Scintillator for Synchrotron-Based Hard X-Ray Micro-Imaging," IEEE Trans. Nucl. Sci., vol. 56, no. 3, pp. 1412-1418, Jun. 2009.

[6] R. P. Murrie, K. S. Morgan, A. Maksimenko, A. Fouras, D. M. Paganin, C. Hall, K. K. W. Siu, D. W. 
Parsons, and M. Donnelley, "Live small-animal X-ray lung velocimetry and lung microtomography at the Australian Synchrotron Imaging and Medical Beamline.," J. Synchrotron Radiat., vol. 22, no. Pt 4, pp. 1049-55, Jul. 2015.

[7] R. Liu, X. Yin, H. Li, Q. Shao, P. York, Y. He, T. Xiao, and J. Zhang, "Visualization and quantitative profiling of mixing and segregation of granules using synchrotron radiation $X$-ray microtomography and three dimensional reconstruction.," Int. J. Pharm., vol. 445, no. 1-2, pp. 125-33, Mar. 2013.

[8] K. Song, E. Yeom, S.-J. Seo, K. Kim, H. Kim, J.-H. Lim, and S. Joon Lee, "Journey of water in pine cones.," Sci. Rep., vol. 5, p. 9963, Jan. 2015.

[9] J. W. Jung, J. S. Lee, N. Kwon, S. J. Park, S. Chang, J. Kim, J. Pyo, Y. Kohmura, Y. Nishino, M. Yamamoto, T. Ishikawa, and J. H. Je, "Fast microtomography using bright monochromatic $\mathrm{X}$-rays.," Rev. Sci. Instrum., vol. 83, no. 9, p. 093704, Sep. 2012.

[10] M. Ebner, F. Marone, M. Stampanoni, and V. Wood, "Visualization and quantification of electrochemical and mechanical degradation in Li ion batteries.," Science, vol. 342, no. 6159, pp. 716-20, Nov. 2013.

[11] F. Basile, P. Benito, S. Bugani, W. De Nolf, G. Fornasari, K. Janssens, L. Morselli, E. Scavetta, D. Tonelli, and A. Vaccari, "Combined Use of Synchrotron-Radiation-Based Imaging Techniques for the Characterization of Structured Catalysts," Adv. Funct. Mater., vol. 20, no. 23, pp. 4117-4126, Dec. 2010.

[12] C. Albert, J. Jameson, P. Smith, and G. Harris, "Reduced diaphyseal strength associated with high intracortical vascular porosity within long bones of children with osteogenesis imperfecta.," Bone, vol. 66, pp. 121-30, Sep. 2014.

[13] J. H. Kinney and M. C. Nichols, "X-Ray Tomographic Microscopy (XTM) Using Synchrotron Radiation," Annu. Rev. Mater. Sci., vol. 22, no. 1, pp. 121-152, Aug. 1992.

[14] Y. Wang, F. De Carlo, D. C. Mancini, I. McNulty, B. Tieman, J. Bresnahan, I. Foster, J. Insley, P. Lane, G. von Laszewski, C. Kesselman, M.-H. Su, and M. Thiebaux, "A high-throughput x-ray microtomography system at the Advanced Photon Source," Rev. Sci. Instrum., vol. 72, no. 4, p. 2062, Apr. 2001.

[15] E. L. Ritman, "Current status of developments and applications of micro-CT.," Annu. Rev. Biomed. Eng., vol. 13, pp. 531-52, Aug. 2011.

[16] S. Bauer, L. de Biasi, S. Glatthaar, L. Toukam, H. Gesswein, and T. Baumbach, "In operando study of the high voltage spinel cathode material $\mathrm{LiNi}(0.5) \mathrm{Mn}(1.5) \mathrm{O} 4$ using two dimensional full-field spectroscopic imaging of Ni and Mn.," Phys. Chem. Chem. Phys., vol. 17, no. 25, pp. 16388-97, Jul. 2015.

[17] J. Chen, C. Wu, J. Tian, W. Li, S. Yu, and Y. Tian, "Three-dimensional imaging of a complex concaved cuboctahedron copper sulfide crystal by x-ray nanotomography," Appl. Phys. Lett., vol. 92, no. 23, p. 233104, Jun. 2008.

[18] J. Lim, H. Kim, and S. Y. Park, "Hard X-ray nanotomography beamline 7C XNI at PLS-II.," J. Synchrotron Radiat., vol. 21, no. Pt 4, pp. 827-31, Jul. 2014.

[19] Y. S. Chu, J. M. Yi, F. De Carlo, Q. Shen, W.-K. Lee, H. J. Wu, C. L. Wang, J. Y. Wang, C. J. Liu, C. H. Wang, S. R. Wu, C. C. Chien, Y. Hwu, A. Tkachuk, W. Yun, M. Feser, K. S. Liang, C. S. Yang, J. H. Je, 
and G. Margaritondo, "Hard-x-ray microscopy with Fresnel zone plates reaches $40 \mathrm{~nm}$ Rayleigh resolution," Appl. Phys. Lett., vol. 92, no. 10, p. 103119, Mar. 2008.

[20] Q. Yuan, K. Zhang, Y. Hong, W. Huang, K. Gao, Z. Wang, P. Zhu, J. Gelb, A. Tkachuk, B. Hornberger, M. Feser, W. Yun, and Z. Wu, "A 30 nm-resolution hard X-ray microscope with X-ray fluorescence mapping capability at BSRF.," J. Synchrotron Radiat., vol. 19, no. Pt 6, pp. 1021-8, Nov. 2012.

[21] Y.-T. Chen, T.-Y. Chen, J. Yi, Y. S. Chu, W.-K. Lee, C.-L. Wang, I. M. Kempson, Y. Hwu, V. Gajdosik, and G. Margaritondo, "Hard x-ray Zernike microscopy reaches $30 \mathrm{~nm}$ resolution.," Opt. Lett., vol. 36, no. 7, pp. 1269-71, Apr. 2011.

[22] J. Wang, Y. Karen Chen, Q. Yuan, A. Tkachuk, C. Erdonmez, B. Hornberger, and M. Feser, "Automated markerless full field hard x-ray microscopic tomography at sub-50 nm 3-dimension spatial resolution," Appl. Phys. Lett., vol. 100, no. 14, p. 143107, Apr. 2012.

[23] J. C. Andrews, F. Meirer, Y. Liu, Z. Mester, and P. Pianetta, "Transmission X-ray microscopy for full-field nano imaging of biomaterials.," Microsc. Res. Tech., vol. 74, no. 7, pp. 671-81, Jul. 2011.

[24] M. A. Le Gros, G. McDermott, and C. A. Larabell, "X-ray tomography of whole cells.," Curr. Opin. Struct. Biol., vol. 15, no. 5, pp. 593-600, 2005.

[25] W. Chao, B. D. Harteneck, J. A. Liddle, E. H. Anderson, and D. T. Attwood, "Soft X-ray microscopy at a spatial resolution better than 15 nm.," Nature, vol. 435, no. 7046, pp. 1210-1213, 2005.

[26] Y. Tian, W. Li, J. Chen, L. Liu, G. Liu, A. Tkachuk, J. Tian, Y. Xiong, J. Gelb, G. Hsu, and W. Yun, "High resolution hard x-ray microscope on a second generation synchrotron source.," Rev. Sci. Instrum., vol. 79, no. 10, p. 103708, Oct. 2008.

[27] J. Miao, T. Ishikawa, I. K. Robinson, and M. M. Murnane, "Beyond crystallography: Diffractive imaging using coherent x-ray light sources," Science (80-. )., vol. 348, no. 6234, pp. 530-535, Apr. 2015.

[28] J. Miao, P. Charalambous, J. Kirz, and D. Sayre, "Extending the methodology of X-ray crystallography to allow imaging of micrometre-sized non-crystalline specimens," vol. 400, no. 6742, pp. 342-344, Jul. 1999.

[29] B. Abbey, K. A. Nugent, G. J. Williams, J. N. Clark, A. G. Peele, M. A. Pfeifer, M. de Jonge, and I. McNulty, "Keyhole coherent diffractive imaging," Nat. Phys., vol. 4, no. 5, pp. 394-398, Mar. 2008.

[30] M. A. Pfeifer, G. J. Williams, I. A. Vartanyants, R. Harder, and I. K. Robinson, "Three-dimensional mapping of a deformation field inside a nanocrystal.," Nature, vol. 442, no. 7098, pp. 63-6, Jul. 2006.

[31] J. Deng, D. J. Vine, S. Chen, Y. S. G. Nashed, Q. Jin, N. W. Phillips, T. Peterka, R. Ross, S. Vogt, and C. J. Jacobsen, "Simultaneous cryo X-ray ptychographic and fluorescence microscopy of green algae.," Proc. Natl. Acad. Sci. U. S. A., vol. 112, no. 8, pp. 2314-9, Feb. 2015.

[32] D. A. Shapiro, Y.-S. Yu, T. Tyliszczak, J. Cabana, R. Celestre, W. Chao, K. Kaznatcheev, A. L. D. Kilcoyne, F. Maia, S. Marchesini, Y. S. Meng, T. Warwick, L. L. Yang, and H. A. Padmore, "Chemical composition mapping with nanometre resolution by soft X-ray microscopy," Nat. Photonics, vol. 8, no. 10, pp. 765-769, Sep. 2014.

[33] M. Holler, A. Diaz, M. Guizar-Sicairos, P. Karvinen, E. Färm, E. Härkönen, M. Ritala, A. Menzel, J. 
Raabe, and O. Bunk, "X-ray ptychographic computed tomography at $16 \mathrm{~nm}$ isotropic 3D resolution.," Sci. Rep., vol. 4, p. 3857, Jan. 2014.

[34] P. Thibault, M. Dierolf, A. Menzel, O. Bunk, C. David, and F. Pfeiffer, "High-resolution scanning xray diffraction microscopy.," Science, vol. 321, no. 5887, pp. 379-82, Jul. 2008.

[35] J. M. Rodenburg, A. C. Hurst, A. G. Cullis, B. R. Dobson, F. Pfeiffer, O. Bunk, C. David, K. Jefimovs, and I. Johnson, "Hard-X-Ray Lensless Imaging of Extended Objects," Phys. Rev. Lett., vol. 98, no. 3, p. 034801, Jan. 2007.

[36] A. Tkachuk, F. Duewer, H. Cui, M. Feser, S. Wang, and W. Yun, "X-ray computed tomography in Zernike phase contrast mode at $8 \mathrm{keV}$ with $50-\mathrm{nm}$ resolution using Cu rotating anode $\mathrm{X}$-ray source," Zeitschrift für Krist., vol. 222, no. 11/2007, pp. 650-655, Jan. 2007.

[37] H. N. Chapman and K. A. Nugent, "Coherent lensless X-ray imaging," Nat. Photonics, vol. 4, no. 12, pp. 833-839, Dec. 2010.

[38] G. van der Schot, M. Svenda, F. R. N. C. Maia, M. Hantke, D. P. DePonte, M. M. Seibert, A. Aquila, J. Schulz, R. Kirian, M. Liang, F. Stellato, B. Iwan, J. Andreasson, N. Timneanu, D. Westphal, F. N. Almeida, D. Odic, D. Hasse, G. H. Carlsson, D. S. D. Larsson, A. Barty, A. V Martin, S. Schorb, C. Bostedt, J. D. Bozek, D. Rolles, A. Rudenko, S. Epp, L. Foucar, B. Rudek, R. Hartmann, N. Kimmel, P. Holl, L. Englert, N.-T. Duane Loh, H. N. Chapman, I. Andersson, J. Hajdu, and T. Ekeberg, "Imaging single cells in a beam of live cyanobacteria with an X-ray laser.," Nat. Commun., vol. 6, p. 5704, Jan. 2015.

[39] J. Miao, K. O. Hodgson, T. Ishikawa, C. A. Larabell, M. A. LeGros, and Y. Nishino, "Imaging whole Escherichia coli bacteria by using single-particle x-ray diffraction.," Proc. Natl. Acad. Sci. U. S. A., vol. 100, no. 1, pp. 110-2, Jan. 2003.

[40] M. R. Howells, T. Beetz, H. N. Chapman, C. Cui, J. M. Holton, C. J. Jacobsen, J. Kirz, E. Lima, S. Marchesini, H. Miao, D. Sayre, D. A. Shapiro, J. C. H. Spence, and D. Starodub, "An assessment of the resolution limitation due to radiation-damage in x-ray diffraction microscopy.," J. Electron Spectros. Relat. Phenomena, vol. 170, no. 1-3, pp. 4-12, Mar. 2009.

[41] Q. Shen, I. Bazarov, and P. Thibault, "Diffractive imaging of nonperiodic materials with future coherent X-ray sources.," J. Synchrotron Radiat., vol. 11, no. Pt 5, pp. 432-8, Sep. 2004.

[42] A. Sakdinawat and D. Attwood, "Nanoscale X-ray imaging," Nat. Photonics, vol. 4, no. 12, pp. 840-848, Dec. 2010.

[43] D. F. Swinehart, "The Beer-Lambert Law," J. Chem. Educ., vol. 39, no. 7, p. 333, Jul. 1962.

[44] Y. Liu, J. Nelson, C. Holzner, J. C. Andrews, and P. Pianetta, "Recent advances in synchrotronbased hard x-ray phase contrast imaging," J. Phys. D. Appl. Phys., vol. 46, no. 49, p. 494001, Dec. 2013.

[45] H. Simons, A. King, W. Ludwig, C. Detlefs, W. Pantleon, S. Schmidt, I. Snigireva, A. Snigirev, and H. F. Poulsen, "Dark-field X-ray microscopy for multiscale structural characterization.," Nat. Commun., vol. 6, p. 6098, Jan. 2015.

[46] S. Vogt, H. N. Chapman, C. Jacobsen, and R. Medenwaldt, "Dark field X-ray microscopy: the effects of condenser/detector aperture," Ultramicroscopy, vol. 87, no. 1-2, pp. 25-44, Mar. 2001.

[47] F. Pfeiffer, M. Bech, O. Bunk, P. Kraft, E. F. Eikenberry, C. Brönnimann, C. Grünzweig, and C. David, 
"Hard-X-ray dark-field imaging using a grating interferometer.," Nat. Mater., vol. 7, no. 2, pp. 134-7, Feb. 2008.

[48] T. L. Kao, C. Y. Shi, J. Wang, W. L. Mao, Y. Liu, and W. Yang, "Nanoscale elemental sensitivity study of $\mathrm{Nd}_{2} \mathrm{Fe}_{14} \mathrm{~B}$ using absorption correlation tomography.," Microsc. Res. Tech., vol. 76, no. 11, pp. 1112-7, Nov. 2013.

[49] Y. Karen Chen-Wiegart, W. M. Harris, J. J. Lombardo, W. K. S. Chiu, and J. Wang, "Oxidation states study of nickel in solid oxide fuel cell anode using x-ray full-field spectroscopic nano-tomography," Appl. Phys. Lett., vol. 101, no. 25, p. 253901, Dec. 2012.

[50] S. Mayo, M. Josh, Y. Nesterets, L. Esteban, M. Pervukhina, M. Ben Clennell, A. Maksimenko, and C. Hall, "Quantitative micro-porosity characterization using synchrotron micro-CT and xenon K-edge subtraction in sandstones, carbonates, shales and coal," Fuel, vol. 154, pp. 167-173, Aug. 2015.

[51] C. Rau, A. Somogyi, and A. Simionovici, "Microimaging and tomography with chemical speciation," Nucl. Instruments Methods Phys. Res. Sect. B Beam Interact. with Mater. Atoms, vol. 200, pp. 444-450, Jan. 2003.

[52] G.-C. Yin, M.-T. Tang, Y.-F. Song, F.-R. Chen, K. S. Liang, F. W. Duewer, W. Yun, C.-H. Ko, and H.-P. D. Shieh, "Energy-tunable transmission $x$-ray microscope for differential contrast imaging with near 60 nm resolution tomography," Appl. Phys. Lett., vol. 88, no. 24, p. 241115, Jun. 2006.

[53] P. Guttmann, C. Bittencourt, S. Rehbein, P. Umek, X. Ke, G. Van Tendeloo, C. P. Ewels, and G. Schneider, "Nanoscale spectroscopy with polarized X-rays by NEXAFS-TXM," Nat. Photonics, vol. 6, no. 1, pp. 25-29, Nov. 2011.

[54] K. Tsuji, K. Nakano, and X. Ding, "Development of confocal micro X-ray fluorescence instrument using two X-ray beams," Spectrochim. Acta Part B At. Spectrosc., vol. 62, no. 6-7, pp. 549-553, Jul. 2007.

[55] G. J. Havrilla and T. Miller, "Micro X-ray fluorescence in materials characterization," Powder Diffr., vol. 19, no. 02, pp. 119-126, Mar. 2012.

[56] U. E. A. Fittschen and G. Falkenberg, "Confocal MXRF in environmental applications," Anal. Bioanal. Chem., vol. 400, no. 6, pp. 1743-1750, Apr. 2011.

[57] N. L. Cordes, S. Seshadri, G. J. Havrilla, X. Yuan, M. Feser, and B. M. Patterson, "Three dimensional subsurface elemental identification of minerals using confocal micro-X-ray fluorescence and micro-X-ray computed tomography," Spectrochim. Acta Part B At. Spectrosc., vol. 103-104, pp. 144-154, Jan. 2015.

[58] F. P. Romano, C. Caliri, L. Cosentino, S. Gammino, L. Giuntini, D. Mascali, L. Neri, L. Pappalardo, F. Rizzo, and F. Taccetti, "Macro and Micro Full Field X-Ray Fluorescence with an X-Ray Pinhole Camera Presenting High Energy and High Spatial Resolution," Anal. Chem., vol. 86, no. 21, pp. 10892-10899, Nov. 2014.

[59] E. Nazaretski, K. Lauer, H. Yan, N. Bouet, J. Zhou, R. Conley, X. Huang, W. Xu, M. Lu, K. Gofron, S. Kalbfleisch, U. Wagner, C. Rau, and Y. S. Chu, "Pushing the limits: an instrument for hard X-ray imaging below 20 nm.," J. Synchrotron Radiat., vol. 22, no. Pt 2, pp. 336-41, Mar. 2015.

[60] S. Chen, J. Deng, Y. Yuan, C. Flachenecker, R. Mak, B. Hornberger, Q. Jin, D. Shu, B. Lai, J. Maser, C. Roehrig, T. Paunesku, S. C. Gleber, D. J. Vine, L. Finney, J. VonOsinski, M. Bolbat, I. Spink, Z. Chen, J. Steele, D. Trapp, J. Irwin, M. Feser, E. Snyder, K. Brister, C. Jacobsen, G. Woloschak, and S. Vogt, 
"The Bionanoprobe: hard X-ray fluorescence nanoprobe with cryogenic capabilities.," J. Synchrotron Radiat., vol. 21, no. Pt 1, pp. 66-75, Jan. 2014.

[61] R. P. Winarski, M. V Holt, V. Rose, P. Fuesz, D. Carbaugh, C. Benson, D. Shu, D. Kline, G. B. Stephenson, I. McNulty, and J. Maser, "A hard X-ray nanoprobe beamline for nanoscale microscopy.," J. Synchrotron Radiat., vol. 19, no. Pt 6, pp. 1056-60, Nov. 2012.

[62] M. Korbas, S. R. Blechinger, P. H. Krone, I. J. Pickering, and G. N. George, "Localizing organomercury uptake and accumulation in zebrafish larvae at the tissue and cellular level.," Proc. Natl. Acad. Sci. U. S. A., vol. 105, no. 34, pp. 12108-12, Aug. 2008.

[63] S. R. Deans, The Radon transform and some of its applications. Wiley, 1983.

[64] R. Gordon, R. Bender, and G. T. Herman, "Algebraic Reconstruction Techniques (ART) for threedimensional electron microscopy and X-ray photography," J. Theor. Biol., vol. 29, no. 3, pp. 471481, Dec. 1970.

[65] L. A. Shepp and Y. Vardi, "Maximum likelihood reconstruction for emission tomography.," IEEE Trans. Med. Imaging, vol. 1, no. 2, pp. 113-22, Jan. 1982.

[66] H. Erdogan and J. A. Fessler, "Ordered subsets algorithms for transmission tomography.," Phys. Med. Biol., vol. 44, no. 11, pp. 2835-51, Nov. 1999.

[67] K. Choi, J. Wang, L. Zhu, T.-S. Suh, S. Boyd, and L. Xing, "Compressed sensing based cone-beam computed tomography reconstruction with a first-order method.," Med. Phys., vol. 37, no. 9, pp. 5113-25, Sep. 2010.

[68] G.-H. Chen, J. Tang, and S. Leng, "Prior image constrained compressed sensing (PICCS): a method to accurately reconstruct dynamic CT images from highly undersampled projection data sets.," Med. Phys., vol. 35, no. 2, pp. 660-3, Feb. 2008.

[69] J. Miao, F. Förster, and O. Levi, "Equally sloped tomography with oversampling reconstruction," Phys. Rev. B, vol. 72, no. 5, p. 052103, Aug. 2005.

[70] M. C. Scott, C.-C. Chen, M. Mecklenburg, C. Zhu, R. Xu, P. Ercius, U. Dahmen, B. C. Regan, and J. Miao, "Electron tomography at 2.4-ångström resolution," Nature, vol. 483, no. 7390, pp. 444-447, Mar. 2012.

[71] M. Guizar-Sicairos, J. J. Boon, K. Mader, A. Diaz, A. Menzel, and O. Bunk, "Quantitative interior xray nanotomography by a hybrid imaging technique," Optica, vol. 2, no. 3, p. 259, Mar. 2015.

[72] M. Guizar-Sicairos, A. Diaz, M. Holler, M. S. Lucas, A. Menzel, R. A. Wepf, and O. Bunk, "Phase tomography from x-ray coherent diffractive imaging projections.," Opt. Express, vol. 19, no. 22, pp. 21345-57, Oct. 2011.

[73] Y. Yang, F. Yang, F. F. Hingerl, X. Xiao, Y. Liu, Z. Wu, S. M. Benson, M. F. Toney, J. C. Andrews, and P. Pianetta, "Registration of the rotation axis in X-ray tomography.," J. Synchrotron Radiat., vol. 22, no. Pt 2, pp. 452-7, Mar. 2015.

[74] B. S. Reddy and B. N. Chatterji, "An FFT-based technique for translation, rotation, and scaleinvariant image registration.," IEEE Trans. Image Process., vol. 5, no. 8, pp. 1266-71, Jan. 1996.

[75] R. Szeliski, "Image alignment and stitching," in Handbook of Mathematical Models in Computer Vision, 2006, pp. 273-292. 
[76] D. G. Lowe, "Distinctive image features from scale-invariant keypoints," Int. J. Comput. Vis., vol. 60, pp. 91-110, 2004.

[77] A. Vedaldi and B. Fulkerson, "VLFeat - An open and portable library of computer vision algorithms," Design, vol. 3, pp. 1-4, 2010.

[78] H. Bay, A. Ess, T. Tuytelaars, and L. Van Gool, "Speeded-Up Robust Features (SURF)," Comput. Vis. Image Underst., vol. 110, pp. 346-359, 2008.

[79] A. Burvall, U. Lundström, P. A. C. Takman, D. H. Larsson, and H. M. Hertz, "Phase retrieval in X-ray phase-contrast imaging suitable for tomography.," Opt. Express, vol. 19, no. 11, pp. 10359-76, May 2011.

[80] Y. Liu, J. Wang, Y. Hong, Z. Wang, K. Zhang, P. A. Williams, P. Zhu, J. C. Andrews, P. Pianetta, and Z. $\mathrm{Wu}$, "Extended depth of focus for transmission x-ray microscope.," Opt. Lett., vol. 37, no. 17, pp. 3708-10, Sep. 2012.

[81] J. B. T. M. Roerdink and A. Meijster, "The watershed transform: definitions, algorithms and parallelization strategies," Fundam. Informaticae, vol. 41, no. 1-2, pp. 187-228, Jan. 2000.

[82] G. J. Nelson, A. Nakajo, B. N. Cassenti, M. B. DeGostin, K. R. Bagshaw, A. A. Peracchio, G. Xiao, S. Wang, F. Chen, and W. K. S. Chiu, "A rapid analytical assessment tool for three dimensional electrode microstructural networks with geometric sensitivity," J. Power Sources, vol. 246, pp. 322-334, Jan. 2014.

[83] J. S. Cronin, Y. K. Chen-Wiegart, J. Wang, and S. A. Barnett, "Three-dimensional reconstruction and analysis of an entire solid oxide fuel cell by full-field transmission X-ray microscopy," J. Power Sources, vol. 233, pp. 174-179, Jul. 2013.

[84] A. J. Shahani, E. Begum Gulsoy, J. W. Gibbs, J. L. Fife, and P. W. Voorhees, "Integrated approach to the data processing of four-dimensional datasets from phase-contrast x-ray tomography.," Opt. Express, vol. 22, no. 20, pp. 24606-21, Oct. 2014.

[85] H. H. Barrett and K. J. Myers, Foundations of image science. Wiley-Interscience, 2004.

[86] A. Rose, "The Sensitivity Performance of the Human Eye on an Absolute Scale," J. Opt. Soc. Am., vol. 38, no. 2, p. 196, Feb. 1948.

[87] J. T. Bushberg, J. A. Seibert, E. M. Leidholdt, and J. M. Boone, The Essential Physics of Medical Imaging. Lippincott Williams \& Wilkins, 2011.

[88] B. M. Patterson and C. E. Hamilton, "Dimensional standard for micro X-ray computed tomography.," Anal. Chem., vol. 82, no. 20, pp. 8537-43, Oct. 2010.

[89] G. Harauz and M. Van Heel, "Exact filters for general geometry three dimensional reconstruction," Optik (Stuttg)., vol. 73, no. 4, pp. 146-156.

[90] M. van Heel and M. Schatz, "Fourier shell correlation threshold criteria.," J. Struct. Biol., vol. 151, no. 3, pp. 250-62, Sep. 2005.

[91] C. Y. Shi, L. Zhang, W. Yang, Y. Liu, J. Wang, Y. Meng, J. C. Andrews, and W. L. Mao, "Formation of an interconnected network of iron melt at Earth's lower mantle conditions," Nat. Geosci., vol. 6, no. 11, pp. 971-975, Oct. 2013.

[92] E. J. Clowney, M. A. LeGros, C. P. Mosley, F. G. Clowney, E. C. Markenskoff-Papadimitriou, M. 
Myllys, G. Barnea, C. A. Larabell, and S. Lomvardas, "Nuclear aggregation of olfactory receptor genes governs their monogenic expression.," Cell, vol. 151, no. 4, pp. 724-37, Nov. 2012.

[93] R. H. Webb, "Confocal optical microscopy," Reports Prog. Phys., vol. 59, no. 3, pp. 427-471, Mar. 1996.

[94] M. J. Rust, M. Bates, and X. Zhuang, "Sub-diffraction-limit imaging by stochastic optical reconstruction microscopy (STORM).," Nat. Methods, vol. 3, no. 10, pp. 793-5, Oct. 2006.

[95] E. Betzig, G. H. Patterson, R. Sougrat, O. W. Lindwasser, S. Olenych, J. S. Bonifacino, M. W. Davidson, J. Lippincott-Schwartz, and H. F. Hess, "Imaging intracellular fluorescent proteins at nanometer resolution.," Science, vol. 313, no. 5793, pp. 1642-5, Sep. 2006.

[96] Q. Jin, S. Vogt, B. Lai, S. Chen, L. Finney, S.-C. Gleber, J. Ward, J. Deng, R. Mak, N. Moonier, and C. Jacobsen, "Ultraviolet germicidal irradiation and its effects on elemental distributions in mouse embryonic fibroblast cells in x-ray fluorescence microanalysis.," PLoS One, vol. 10, no. 2, p. e0117437, Jan. 2015.

[97] E. A. Smith, B. P. Cinquin, M. Do, G. McDermott, M. A. Le Gros, and C. A. Larabell, "Correlative cryogenic tomography of cells using light and soft x-rays.," Ultramicroscopy, vol. 143, pp. 33-40, Aug. 2014.

[98] M. A. Anastasio, Y. Zou, E. Y. Sidky, and X. Pan, "Local cone-beam tomography image reconstruction on chords.," J. Opt. Soc. Am. A. Opt. Image Sci. Vis., vol. 24, no. 6, pp. 1569-79, Jun. 2007.

[99] H. Li, X. Yin, J. Ji, L. Sun, Q. Shao, P. York, T. Xiao, Y. He, and J. Zhang, "Microstructural investigation to the controlled release kinetics of monolith osmotic pump tablets via synchrotron radiation X-ray microtomography.," Int. J. Pharm., vol. 427, no. 2, pp. 270-5, May 2012.

[100] P. R. Shearing, N. P. Brandon, J. Gelb, R. Bradley, P. J. Withers, A. J. Marquis, S. Cooper, and S. J. Harris, "Multi Length Scale Microstructural Investigations of a Commercially Available Li-Ion Battery Electrode," J. Electrochem. Soc., vol. 159, no. 7, pp. A1023-A1027, Jan. 2012.

[101] P. R. Shearing, J. Gelb, J. Yi, W.-K. Lee, M. Drakopolous, and N. P. Brandon, "Analysis of triple phase contact in Ni-YSZ microstructures using non-destructive X-ray tomography with synchrotron radiation," Electrochem. commun., vol. 12, no. 8, pp. 1021-1024, Aug. 2010.

[102] X. Yin, H. Li, R. Liu, J. Chen, J. Ji, J. Chen, Q. Shao, T. Xiao, P. York, Y. He, and J. Zhang, "Fractal structure determines controlled release kinetics of monolithic osmotic pump tablets.," J. Pharm. Pharmacol., vol. 65, no. 7, pp. 953-9, Jul. 2013.

[103] X. Yin, H. Li, Z. Guo, L. Wu, F. Chen, M. de Matas, Q. Shao, T. Xiao, P. York, Y. He, and J. Zhang, "Quantification of swelling and erosion in the controlled release of a poorly water-soluble drug using synchrotron X-ray computed microtomography.," AAPS J., vol. 15, no. 4, pp. 1025-34, Oct. 2013.

[104] Y. Guan, Y. Gong, W. Li, J. Gelb, L. Zhang, G. Liu, X. Zhang, X. Song, C. Xia, Y. Xiong, H. Wang, Z. Wu, and Y. Tian, "Quantitative analysis of micro structural and conductivity evolution of Ni-YSZ anodes during thermal cycling based on nano-computed tomography," J. Power Sources, vol. 196, no. 24, pp. 10601-10605, Dec. 2011.

[105] P. R. Shearing, R. S. Bradley, J. Gelb, S. N. Lee, A. Atkinson, P. J. Withers, and N. P. Brandon, "Using Synchrotron X-Ray Nano-CT to Characterize SOFC Electrode Microstructures in Three- 
Dimensions at Operating Temperature," Electrochem. Solid-State Lett., vol. 14, no. 10, p. B117, Oct. 2011.

[106] C. L. Evans, E. M. Wightman, and X. Yuan, "Quantifying mineral grain size distributions for process modelling using X-ray micro-tomography," Miner. Eng., Apr. 2015.

[107] Y. Guan, W. Li, Y. Gong, G. Liu, X. Zhang, J. Chen, J. Gelb, W. Yun, Y. Xiong, Y. Tian, and H. Wang, "Analysis of the three-dimensional microstructure of a solid-oxide fuel cell anode using nano $X-$ ray tomography," J. Power Sources, vol. 196, no. 4, pp. 1915-1919, Feb. 2011.

[108] Y. K. Chen-Wiegart, R. DeMike, C. Erdonmez, K. Thornton, S. A. Barnett, and J. Wang, "Tortuosity characterization of 3D microstructure at nano-scale for energy storage and conversion materials," J. Power Sources, vol. 249, pp. 349-356, Mar. 2014.

[109] F. Yang, F. F. Hingerl, X. Xiao, Y. Liu, Z. Wu, S. M. Benson, and M. F. Toney, "Extraction of poremorphology and capillary pressure curves of porous media from synchrotron-based tomography data.," Sci. Rep., vol. 5, p. 10635, Jan. 2015.

[110] F. Yang, Y. Liu, S. K. Martha, Z. Wu, J. C. Andrews, G. E. Ice, P. Pianetta, and J. Nanda, “Nanoscale morphological and chemical changes of high voltage lithium-manganese rich NMC composite cathodes with cycling.," Nano Lett., vol. 14, no. 8, pp. 4334-41, Aug. 2014.

[111] J. Wang, C. Eng, Y.-C. K. Chen-Wiegart, and J. Wang, "Probing three-dimensional sodiationdesodiation equilibrium in sodium-ion batteries by in situ hard X-ray nanotomography.," Nat. Commun., vol. 6, p. 7496, Jan. 2015.

[112] M. Allahkarami, S. Bandla, R. P. Winarski, and J. C. Hanan, "X-ray nanotomography of a nanofiber: Quantitative measurement of diameter fluctuations," Appl. Surf. Sci., vol. 297, pp. 9-15, Apr. 2014.

[113] Y. Guan, W. Li, Y. Gong, G. Liu, J. Gelb, X. Zhang, Y. Xiong, Y. Tian, and H. Wang, "The study of the reconstructed three-dimensional structure of a solid-oxide fuel-cell cathode by X-ray nanotomography.," J. Synchrotron Radiat., vol. 17, no. 6, pp. 782-5, Dec. 2010.

[114] W. M. Harris and W. K. S. Chiu, "Determining the representative volume element size for threedimensional microstructural material characterization. Part 2: Application to experimental data," J. Power Sources, vol. 282, pp. 622-629, May 2015.

[115] W. M. Harris and W. K. S. Chiu, "Determining the representative volume element size for threedimensional microstructural material characterization. Part 1: Predictive models," J. Power Sources, vol. 282, pp. 552-561, May 2015.

[116] J. T. Gostick and A. Z. Weber, "Resistor-Network Modeling of Ionic Conduction in Polymer Electrolytes," Electrochim. Acta, Mar. 2015.

[117] Z. Jiang, M. I. J. van Dijke, K. Wu, G. D. Couples, K. S. Sorbie, and J. Ma, "Stochastic Pore Network Generation from 3D Rock Images," Transp. Porous Media, vol. 94, no. 2, pp. 571-593, Jun. 2011.

[118] C. David, Y. Gueguen, and G. Pampoukis, "Effective medium theory and network theory applied to the transport properties of rock," J. Geophys. Res., vol. 95, no. B5, p. 6993, 1990.

[119] F. Meirer, S. Kalirai, D. Morris, S. Soparawalla, Y. Liu, G. Mesu, J. C. Andrews, and B. M. Weckhuysen, "Life and death of a single catalytic cracking particle," Sci. Adv., vol. 1, no. 3, p. e1400199, Apr. 2015. 
[120] P. -E. Øren, S. Bakke, and O. J. Arntzen, "A Priori Prediction of Relative Permeability and Capillary Pressure from Pore-Scale Modelling," in IOR 1997 - 9th European Symposium on Improved Oil Recovery, 1997.

[121] M. B. DeGostin, A. Nakajo, B. N. Cassenti, A. A. Peracchio, G. J. Nelson, and W. K. S. Chiu, "Geometric sensitivity of electrochemical fin shape on three dimensional microstructure network conductivity analysis," J. Power Sources, vol. 291, pp. 181-194, Sep. 2015.

[122] G. J. Nelson, A. A. Peracchio, and W. K. S. Chiu, "Analytical investigations of varying cross section microstructures on charge transfer in solid oxide fuel cell electrodes," J. Power Sources, vol. 196, no. 10, pp. 4695-4704, May 2011.

[123] F. Arfelli, "Synchrotron light and imaging systems for medical radiology," Nucl. Instruments Methods Phys. Res. Sect. A Accel. Spectrometers, Detect. Assoc. Equip., vol. 454, no. 1, pp. 11-25, Nov. 2000.

[124] M. Karçaaltıncaba and A. Aktaş, "Dual-energy CT revisited with multidetector CT: review of principles and clinical applications.," Diagn. Interv. Radiol., vol. 17, no. 3, pp. 181-94, Sep. 2011.

[125] F. Lin, D. Nordlund, Y. Li, M. K. Quan, L. Cheng, T.-C. Weng, Y. Liu, H. L. Xin, and M. M. Doeff, "Metal segregation in hierarchically structured cathode materials for high-energy lithium batteries," Nat. Energy, vol. 1, no. 1, p. 15004, Jan. 2016.

[126] E. Hu, S.-M. Bak, Y. Liu, J. Liu, X. Yu, Y.-N. Zhou, J. Zhou, P. Khalifah, K. Ariyoshi, K.-W. Nam, and X.-Q. Yang, "Utilizing Environmental Friendly Iron as a Substitution Element in Spinel Structured Cathode Materials for Safer High Energy Lithium-Ion Batteries," Adv. Energy Mater., Dec. 2015.

[127] I. D. Gonzalez-Jimenez, K. Cats, T. Davidian, M. Ruitenbeek, F. Meirer, Y. Liu, J. Nelson, J. C. Andrews, P. Pianetta, F. M. F. de Groot, and B. M. Weckhuysen, "Hard X-ray Nanotomography of Catalytic Solids at Work," Angew. Chemie, vol. 124, no. 48, pp. 12152-12156, Nov. 2012.

[128] F. Meirer, D. T. Morris, S. Kalirai, Y. Liu, J. C. Andrews, and B. M. Weckhuysen, "Mapping metals incorporation of a whole single catalyst particle using element specific X-ray nanotomography.," J. Am. Chem. Soc., vol. 137, no. 1, pp. 102-5, Jan. 2015.

[129] F. Meirer, S. Kalirai, J. Nelson Weker, Y. Liu, J. C. Andrews, and B. M. Weckhuysen, "Agglutination of single catalyst particles during fluid catalytic cracking as observed by X-ray nanotomography.," Chem. Commun. (Camb)., vol. 51, no. 38, pp. 8097-100, May 2015.

[130] T. L. Kao, C. Y. Shi, J. Wang, W. L. Mao, Y. Liu, and W. Yang, "Nanoscale elemental sensitivity study of Nd2Fe14B using absorption correlation tomography," Microsc. Res. Tech., vol. 76, pp. 11121117, 2013.

[131] W. M. Harris, J. J. Lombardo, M. B. DeGostin, G. J. Nelson, H. Luebbe, J. A. Schuler, J. Van herle, J. C. Andrews, Y. Liu, P. Pianetta, Y.-C. Karen Chen, J. Wang, and W. K. S. Chiu, "Three-dimensional microstructural mapping of poisoning phases in the Neodymium Nickelate solid oxide fuel cell cathode," Solid State lonics, vol. 237, pp. 16-21, Apr. 2013.

[132] C. Donnelly, M. Guizar-Sicairos, V. Scagnoli, M. Holler, T. Huthwelker, A. Menzel, I. Vartiainen, E. Müller, E. Kirk, S. Gliga, J. Raabe, and L. J. Heyderman, "Element-Specific X-Ray Phase Tomography of 3D Structures at the Nanoscale," Phys. Rev. Lett., vol. 114, no. 11, p. 115501, Mar. 2015.

[133] G. J. Nelson, W. M. Harris, J. R. Izzo, K. N. Grew, W. K. S. Chiu, Y. S. Chu, J. Yi, J. C. Andrews, Y. Liu, 
and P. Pianetta, "Three-dimensional mapping of nickel oxidation states using full field x-ray absorption near edge structure nanotomography," Appl. Phys. Lett., vol. 98, no. 17, p. 173109, Apr. 2011.

[134] F. Meirer, J. Cabana, Y. Liu, A. Mehta, J. C. Andrews, and P. Pianetta, "Three-dimensional imaging of chemical phase transformations at the nanoscale with full-field transmission X-ray microscopy.," J. Synchrotron Radiat., vol. 18, no. Pt 5, pp. 773-781, 2011.

[135] Y. Liu, F. Meirer, P. A. Williams, J. Wang, J. C. Andrews, and P. Pianetta, "TXM-Wizard: a program for advanced data collection and evaluation in full-field transmission X-ray microscopy.," J. Synchrotron Radiat., vol. 19, no. Pt 2, pp. 281-7, Mar. 2012.

[136] B. K. Teo, EXAFS: Basic Principles and Data Analysis, vol. 9. Berlin, Heidelberg: Springer Berlin Heidelberg, 1986.

[137] T.-C. Weng, G. S. Waldo, and J. E. Penner-Hahn, "A method for normalization of X-ray absorption spectra.," J. Synchrotron Radiat., vol. 12, no. Pt 4, pp. 506-10, Jul. 2005.

[138] L. Li, Y. K. Chen-Wiegart, J. Wang, P. Gao, Q. Ding, Y.-S. Yu, F. Wang, J. Cabana, J. Wang, and S. Jin, "Visualization of electrochemically driven solid-state phase transformations using operando hard X-ray spectro-imaging.," Nat. Commun., vol. 6, p. 6883, Jan. 2015.

[139] M. Lerotic, R. Mak, S. Wirick, F. Meirer, and C. Jacobsen, "MANTiS: a program for the analysis of X-ray spectromicroscopy data.," J. Synchrotron Radiat., vol. 21, no. Pt 5, pp. 1206-12, Sep. 2014.

[140] U. Boesenberg, F. Meirer, Y. Liu, A. K. Shukla, R. Dell'anna, T. Tyliszczak, G. Chen, J. C. Andrews, T. J. Richardson, R. Kostecki, and J. Cabana, "Mesoscale phase distribution in single particles of LiFePO4 following lithium deintercalation.," Chem. Mater., vol. 25, no. 9, pp. 1664-1672, May 2013.

[141] S. C. Mayo, A. M. Tulloh, A. Trinchi, and S. Y. S. Yang, "Data-constrained microstructure characterization with multispectrum X-ray micro-CT.," Microsc. Microanal., vol. 18, no. 3, pp. 524-30, Jun. 2012.

[142] Y. S. Yang, K. Y. Liu, S. Mayo, A. Tulloh, M. B. Clennell, and T. Q. Xiao, "A data-constrained modelling approach to sandstone microstructure characterisation," J. Pet. Sci. Eng., vol. 105, pp. 76-83, May 2013.

[143] S. Yang, S. Furman, and A. Tulloh, "A Data-Constrained 3D Model for Material Compositional Microstructures," Adv. Mater. Res., vol. 32, pp. 267-270, Feb. 2008.

[144] Y. Wang, Y. Yang, T. Xiao, K. Liu, B. Clennell, G. Zhang, and H. Wang, "Synchrotron-Based DataConstrained Modeling Analysis of Microscopic Mineral Distributions in Limestone," Int. J. Geosci., vol. 04, no. 02, pp. 344-351, Mar. 2013.

[145] G. Johnson, A. King, M. G. Honnicke, J. Marrow, and W. Ludwig, "X-ray diffraction contrast tomography: a novel technique for three-dimensional grain mapping of polycrystals. II. The combined case," J. Appl. Crystallogr., vol. 41, no. 2, pp. 310-318, Mar. 2008.

[146] W. Ludwig, S. Schmidt, E. M. Lauridsen, and H. F. Poulsen, "X-ray diffraction contrast tomography: a novel technique for three-dimensional grain mapping of polycrystals. I. Direct beam case," J. Appl. Crystallogr., vol. 41, no. 2, pp. 302-309, Mar. 2008.

[147] P. Reischig, A. King, L. Nervo, N. Viganó, Y. Guilhem, W. J. Palenstijn, K. J. Batenburg, M. Preuss, 
and W. Ludwig, "Advances in X-ray diffraction contrast tomography: flexibility in the setup geometry and application to multiphase materials," J. Appl. Crystallogr., vol. 46, no. 2, pp. 297311, Mar. 2013.

[148] W. Ludwig, P. Reischig, A. King, M. Herbig, E. M. Lauridsen, G. Johnson, T. J. Marrow, and J. Y. Buffière, "Three-dimensional grain mapping by $x$-ray diffraction contrast tomography and the use of Friedel pairs in diffraction data analysis.," Rev. Sci. Instrum., vol. 80, no. 3, p. 033905, Mar. 2009.

[149] A. King, P. Reischig, J. Adrien, and W. Ludwig, "First laboratory X-ray diffraction contrast tomography for grain mapping of polycrystals," J. Appl. Crystallogr., vol. 46, no. 6, pp. 1734-1740, Oct. 2013.

[150] S. Peetermans, A. King, W. Ludwig, P. Reischig, and E. H. Lehmann, "Cold neutron diffraction contrast tomography of polycrystalline material.," Analyst, vol. 139, no. 22, pp. 5765-71, Nov. 2014.

[151] W. Ludwig, A. King, P. Reischig, M. Herbig, E. M. Lauridsen, S. Schmidt, H. Proudhon, S. Forest, P. Cloetens, S. R. du Roscoat, J. Y. Buffière, T. J. Marrow, and H. F. Poulsen, "New opportunities for 3D materials science of polycrystalline materials at the micrometre lengthscale by combined use of X-ray diffraction and X-ray imaging," Mater. Sci. Eng. A, vol. 524, no. 1-2, pp. 69-76, Oct. 2009.

[152] Q. Hu, M. Aboustait, M. T. Ley, J. C. Hanan, V. Rose, and R. Winarski, "Combined threedimensional structure and chemistry imaging with nanoscale resolution," Acta Mater., vol. 77, pp. 173-182, Sep. 2014.

[153] E. A. Smith, G. McDermott, M. Do, K. Leung, B. Panning, M. A. Le Gros, and C. A. Larabell, "Quantitatively imaging chromosomes by correlated cryo-fluorescence and soft x-ray tomographies.," Biophys. J., vol. 107, no. 8, pp. 1988-96, Oct. 2014.

[154] R. Carzaniga, M.-C. Domart, L. M. Collinson, and E. Duke, "Cryo-soft X-ray tomography: a journey into the world of the native-state cell.," Protoplasma, vol. 251, no. 2, pp. 449-58, Mar. 2014.

[155] V. Cnudde and M. N. Boone, "High-resolution X-ray computed tomography in geosciences: A review of the current technology and applications," Earth-Science Rev., vol. 123, pp. 1-17, Aug. 2013.

[156] J. Nelson Weker and M. F. Toney, "Emerging In Situ and Operando Nanoscale X-Ray Imaging Techniques for Energy Storage Materials," Adv. Funct. Mater., vol. 25, no. 11, pp. 1622-1637, Mar. 2015.

[157] J. R. Helliwell, C. J. Sturrock, K. M. Grayling, S. R. Tracy, R. J. Flavel, I. M. Young, W. R. Whalley, and S. J. Mooney, "Applications of X-ray computed tomography for examining biophysical interactions and structural development in soil systems: a review," Eur. J. Soil Sci., vol. 64, no. 3, pp. 279-297, Jun. 2013.

[158] I. A. Taina, R. J. Heck, and T. R. Elliot, "Application of X-ray computed tomography to soil science: A literature review," Can. J. Soil Sci., vol. 88, no. 1, pp. 1-19, Feb. 2008.

[159] M. J. Paulus, S. S. Gleason, S. J. Kennel, P. R. Hunsicker, and D. K. Johnson, "High resolution X-ray computed tomography: an emerging tool for small animal cancer research.," Neoplasia, vol. 2, no. 1-2, pp. 62-70, Jan. .

[160] C. Ruprecht, R. Pini, R. Falta, S. Benson, and L. Murdoch, "Hysteretic trapping and relative 
permeability of $\mathrm{CO} 2$ in sandstone at reservoir conditions," Int. J. Greenh. Gas Control, vol. 27, pp. 15-27, Aug. 2014.

[161] Y. Wang, C. Lesher, G. Fiquet, M. L. Rivers, N. Nishiyama, J. Siebert, J. Roberts, G. Morard, S. Gaudio, A. Clark, H. Watson, N. Menguy, and F. Guyot, "In situ high-pressure and hightemperature X-ray microtomographic imaging during large deformation: A new technique for studying mechanical behavior of multiphase composites," Geosphere, vol. 7, no. 1, pp. 40-53, Jan. 2011.

[162] J. Wang, Y.-C. K. Chen-Wiegart, and J. Wang, "In situ three-dimensional synchrotron X-Ray nanotomography of the (de)lithiation processes in tin anodes.," Angew. Chem. Int. Ed. Engl., vol. 53, no. 17, pp. 4460-4, Apr. 2014.

[163] J. N. Weker, N. Liu, S. Misra, J. C. Andrews, Y. Cui, and M. F. Toney, "Insitu nanotomography and operando transmission X-ray microscopy of micron-sized Ge particles," Energy Environ. Sci., vol. 7, no. 8, p. 2771, Jun. 2014.

[164] A. T. Jang, J. D. Lin, Y. Seo, S. Etchin, A. Merkle, K. Fahey, and S. P. Ho, "In situ compressive loading and correlative noninvasive imaging of the bone-periodontal ligament-tooth fibrous joint.," J. Vis. Exp., no. 85, p. e51147, Jan. 2014.

[165] B. Hornberger, H. Bale, A. Merkle, M. Feser, W. Harris, S. Etchin, M. Leibowitz, W. Qiu, A. Tkachuk, A. Gu, R. S. Bradley, X. Lu, P. J. Withers, A. Clarke, K. Henderson, N. Cordes, and B. M. Patterson, "X-ray microscopy for in situ characterization of 3D nanostructural evolution in the laboratory," in SPIE Optical Engineering + Applications, 2015, p. 959200.

[166] D. Z. Chen, C. Y. Shi, Q. An, Q. Zeng, W. L. Mao, W. A. Goddard, and J. R. Greer, "Fractal atomiclevel percolation in metallic glasses.," Science, vol. 349, no. 6254, pp. 1306-10, Sep. 2015.

[167] Y. Lin, Q. Zeng, W. Yang, and W. L. Mao, "Pressure-induced densification in GeO2 glass: A transmission x-ray microscopy study," Appl. Phys. Lett., vol. 103, no. 26, p. 261909, Dec. 2013.

[168] Q. Zeng, Y. Kono, Y. Lin, Z. Zeng, J. Wang, S. V. Sinogeikin, C. Park, Y. Meng, W. Yang, H.-K. Mao, and W. L. Mao, "Universal Fractional Noncubic Power Law for Density of Metallic Glasses," Phys. Rev. Lett., vol. 112, no. 18, p. 185502, May 2014.

[169] Y. Liu, J. Wang, M. Azuma, W. L. Mao, and W. Yang, "Five-dimensional visualization of phase transition in BiNiO3 under high pressure.," Appl. Phys. Lett., vol. 104, no. 4, p. 043108, Jan. 2014.

[170] H. Liu, L. Wang, X. Xiao, F. De Carlo, J. Feng, H.-K. Mao, and R. J. Hemley, "Anomalous highpressure behavior of amorphous selenium from synchrotron x-ray diffraction and microtomography.," Proc. Natl. Acad. Sci. U. S. A., vol. 105, no. 36, pp. 13229-34, Sep. 2008.

[171] W. A. Kalender, "Dose in x-ray computed tomography.," Phys. Med. Biol., vol. 59, no. 3, pp. R129-50, Feb. 2014.

[172] P. K. Nguyen, W. H. Lee, Y. F. Li, W. X. Hong, S. Hu, C. Chan, G. Liang, I. Nguyen, S.-G. Ong, J. Churko, J. Wang, R. B. Altman, D. Fleischmann, and J. C. Wu, "Assessment of the Radiation Effects of Cardiac CT Angiography Using Protein and Genetic Biomarkers," JACC Cardiovasc. Imaging, vol. 8, no. 8, pp. 873-84, Jul. 2015.

[173] O. J. Borkiewicz, K. M. Wiaderek, P. J. Chupas, and K. W. Chapman, "Best Practices for Operando Battery Experiments: Influences of X-ray Experiment Design on Observed Electrochemical Reactivity.," J. Phys. Chem. Lett., vol. 6, no. 11, pp. 2081-5, Jun. 2015. 
[174] J. Nelson, Y. Yang, S. Misra, J. C. Andrews, Y. Cui, and M. F. Toney, "Identifying and managing radiation damage during in situ transmission $\mathrm{x}$-ray microscopy of Li-ion batteries," in SPIE Optical Engineering + Applications, 2013, p. 88510B.

[175] J. Nelson Weker, Y. Li, and W. C. Chueh, "Low dose, limited energy spectroscopic X-ray microscopy," in SPIE Optical Engineering + Applications, 2015, p. 95920N.

[176] R. Hegerl and W. Hoppe, "Influence of Electron Noise on Three-dimensional Image Reconstruction," Zeitschrift für Naturforsch. A, vol. 31, no. 12, Jan. 1976.

[177] H. Lusic and M. W. Grinstaff, "X-ray-computed tomography contrast agents.," Chem. Rev., vol. 113, no. 3, pp. 1641-66, Mar. 2013.

[178] H. Yan, R. Conley, N. Bouet, and Y. S. Chu, "Hard x-ray nanofocusing by multilayer Laue lenses," J. Phys. D. Appl. Phys., vol. 47, no. 26, p. 263001, Jul. 2014.

[179] C. Chang and A. Sakdinawat, "Ultra-high aspect ratio high-resolution nanofabrication for hard Xray diffractive optics.," Nat. Commun., vol. 5, p. 4243, Jan. 2014.

\section{Conflict of interest}

The authors declare no conflict of interest. 


\section{Highlights}

- Review of X-ray microscopy methods that cover a wide range of length scales and provide very rich structural/chemical information.

- Overview of the diversity of modern post-reconstruction analyses performed with 3-dimensional x-ray microscopy data

- Outlook for the future developments in X-ray microscopy. 